\title{
Under The Surface: An Examination Of Voice, Space, And Identity In West Virginia University McNair Scholars
}

Thomas N. Keopuhiwa

West Virginia University

Follow this and additional works at: https://researchrepository.wvu.edu/etd

\section{Recommended Citation}

Keopuhiwa, Thomas N., "Under The Surface: An Examination Of Voice, Space, And Identity In West Virginia University McNair Scholars" (2012). Graduate Theses, Dissertations, and Problem Reports. 209. https://researchrepository.wvu.edu/etd/209

This Dissertation is protected by copyright and/or related rights. It has been brought to you by the The Research Repository @ WVU with permission from the rights-holder(s). You are free to use this Dissertation in any way that is permitted by the copyright and related rights legislation that applies to your use. For other uses you must obtain permission from the rights-holder(s) directly, unless additional rights are indicated by a Creative Commons license in the record and/ or on the work itself. This Dissertation has been accepted for inclusion in WVU Graduate Theses, Dissertations, and Problem Reports collection by an authorized administrator of The Research Repository @ WVU. For more information, please contact researchrepository@mail.wvu.edu. 
Under The Surface: An Examination Of Voice, Space, And Identity In West Virginia University McNair Scholars

Thomas N. Keopuhiwa

Dissertation submitted to the College of Human Resources and Education at West Virginia University in partial fulfillment of the requirements

for the degree of

Doctor of Education

In

Curriculum and Instruction

Committee of Advisors:

Patricia Obenauf, Ed.D., Chair

David Callejo, Ed.D.

Sam Stack, Ph.D.

Barbara Copenhaver-Bailey, Ed.D.

Richard Biffle, Ph.D.

Robert Waterson, Ph.D.

Department of Curriculum \& Instruction/Literacy Studies

Morgantown, West Virginia

2012

Keywords: McNair, First Generation Student, Minority student, space, voice, identity

Copyright (c) Thomas No'eau Keopuhiwa 


\begin{abstract}
Diversity amongst the college campus is a common goal of most American educational institutions of today. However very few are able to achieve this goal. Increasing the diversity of faculty and staff on campus is one way we can address this issue. The McNair Scholars Post Baccalaureate program is a program that provides training and support to those undergraduates from disadvantaged backgrounds and/or underrepresented minority to help them pursue the goal of obtaining a doctoral degree. The qualitative research presented here, provides an overview of the West Virginia University (WVU) McNair scholars' experiences, and their journey within the McNair program. Using a phenomenological approach, we begin to understand what it is like to be a WVU McNair scholar, and how the WVU McNair program, school, and home culture all play a role in shaping their identity. Findings from this study help to recognize that each scholar's experiences are unique. As the McNair scholars move toward their goals of attending graduate school, the findings suggest that the WVU McNair program provides a space where the students are able to form an identity. This identity acts as an anchor as they face the new challenges that await in higher education. To address this issue I conducted nine in-depth interviews with the WVU McNair scholars, observations, document analysis and incorporated my own experiences. With this research, I try to present a portrayal of what it is really like to pursue higher education as a member of an underrepresented minority.
\end{abstract}




\section{Dedication}

This dissertation is dedicated to: Rona, who has always been there-for everything, inspiring me along my journey and helping me realize that I could accomplish things I never thought were possible. My grandparents, mom, dad, older brothers, younger sister, and extended family Aunty Rae, Uncle Ryan, Aunty June, Uncle Jim, Aunty Georgia, and Kyle for their support and encouragement...And to all those who thought they were alone during their educational journey. 


\section{Acknowledgements}

I would like to acknowledge Professor Pat Obenauf, who has helped me to understand what education is really about. As chair of my committee you have gone above and beyond all of my expectations, and is a mentor that I will always look up to. I am very grateful to have worked with Professor David Callejo who has encouraged me to embrace my culture and made me feel like I belonged in higher education. Words cannot express how much of an impact you have had on my life. I would like to thank Professor Sam Stack who has provided me with firm background in educational history and philosophy. To Professor Rich Biffle and Dr. Barbara Copenhaver-Bailey, your support and encouragement during the whole process helped me to finally realize that I was capable of finishing this dissertation. I am very appreciative for Professor Robert Waterson who was there when I thought I hit my last hurdle and would not complete the research. I would like to thank Dr. Mei who from the beginning has been much more than my supervisor, a role model, a person who genuinely cares about everything she does in life, and one day I hope to model the same love and passion you have for your students and colleagues. To all those who worked with the UASC, the times we have shared together helped to keep me grounded when I sometimes felt like calling it quits. Lastly I would like to recognize the West Virginia University McNair Scholars, you all have inspired me in so many ways, your constant reminders, love, and support played an essential part in completing this journey. 


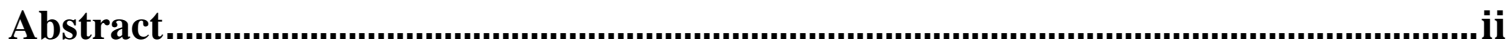

Dedication............................................................................................................ ii

Acknowledgements ...................................................................................................iv

List of tables ........................................................................................................ vii

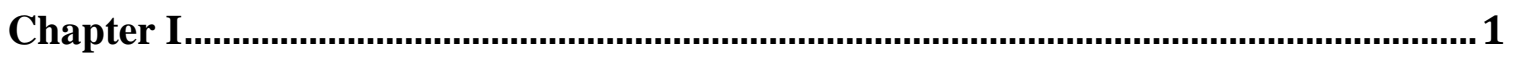

The Life of Ronald E. McNair.....................................................................................................

The Ronald E. McNair Post Baccalaureate Program.........................................................................

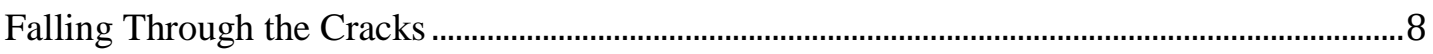

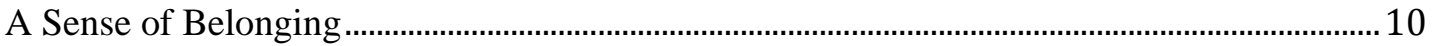

Statement of the Problem........................................................................................... 13

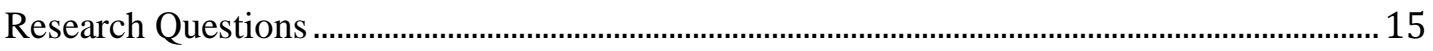

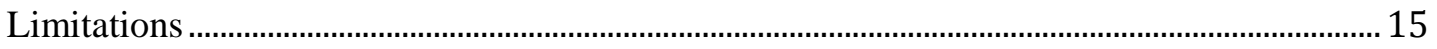

Chapter II ...................................................................................................... 17

Minority and First generation Students in Higher Education........................................... 17

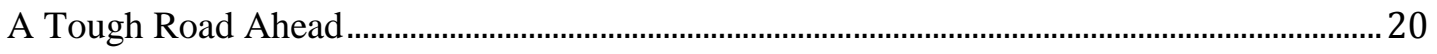

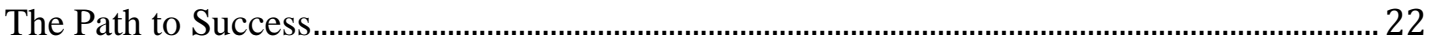

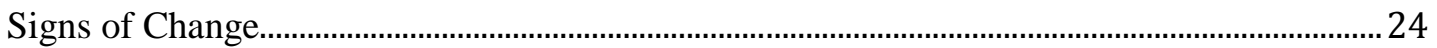

Critical pedagogy as a Theoretical Framework ................................................................ 27

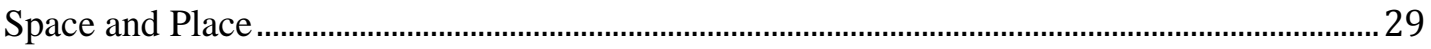

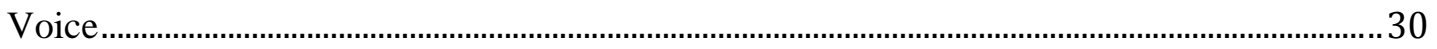

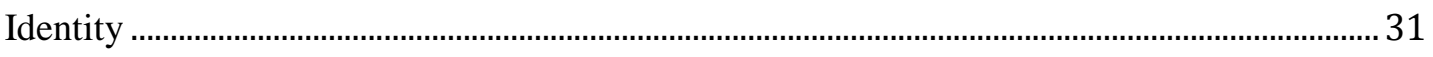

Chapter III …….............................................................................................. 33

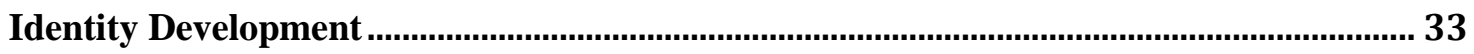

Discovering Who I Am................................................................................................... 33

Identity Development amongst African-Americans ................................................................ 34

Identity Development amongst American Indians ....…………………………………………36

Identity Development amongst Latino/Latina ............................................................................3

Identity Development amongst Asian-Americans....................................................................... 39

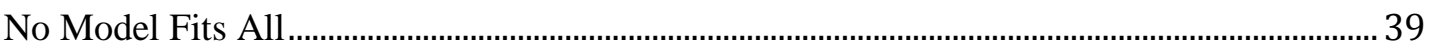

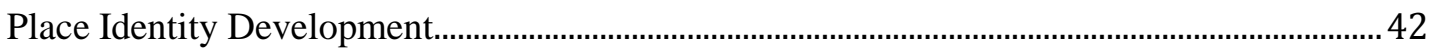

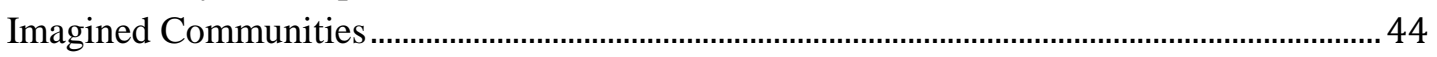

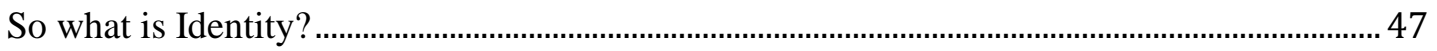

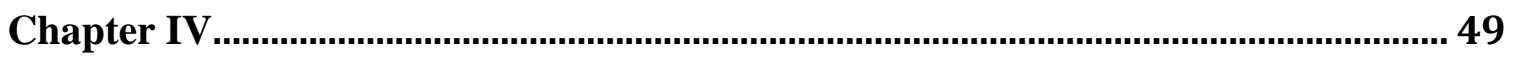

Methods .................................................................................................................. 49

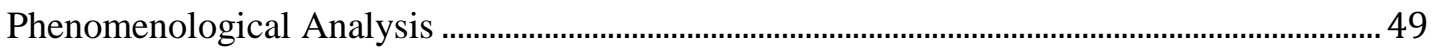

My Own Experience and Observations …………………………...................................................50

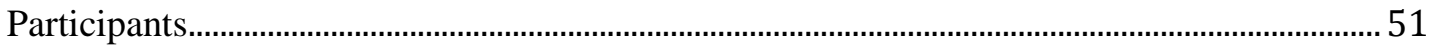




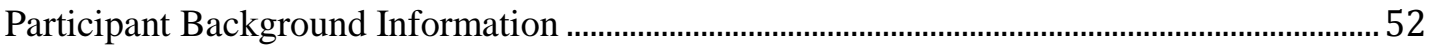

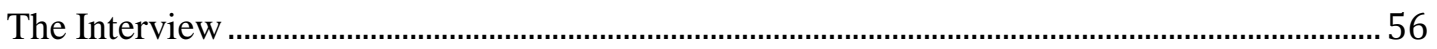

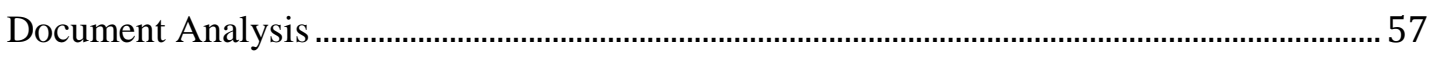

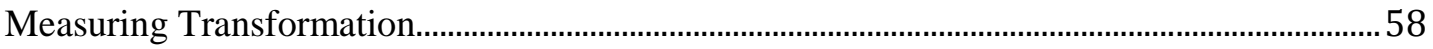

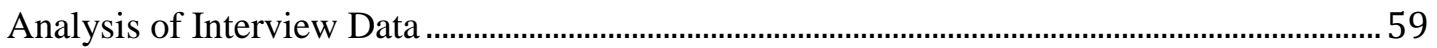

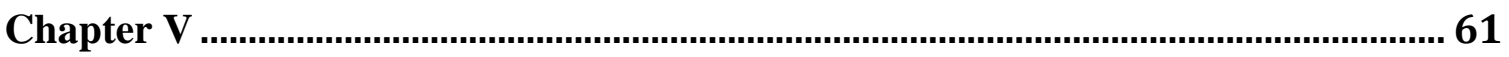

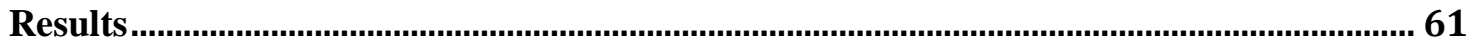

How the McNair Program Affects Student Participants Identity .................................... 62

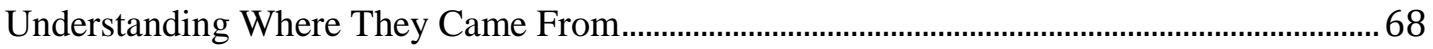

Pre-conceived Notions of Higher Education................................................................................... 73

Within the Walls of the WVU McNair program.......................................................................... 77

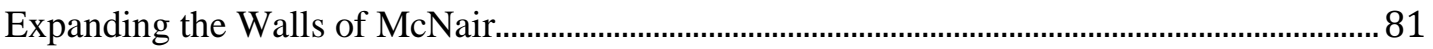

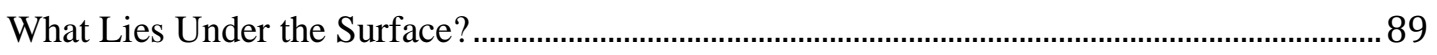

Is There a Transformation That Takes Place ........................................................................... 96

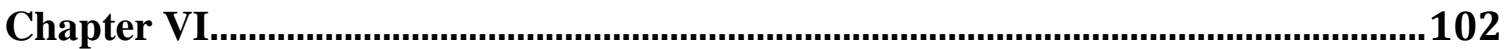

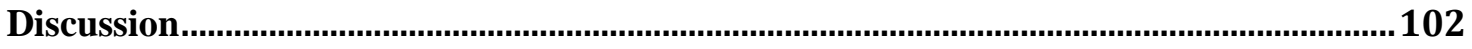

The Effects of the McNair Program on Space ………………………………....................... 103

The Effects of the McNair Program on Voice....................................................................... 105

The Effects of the McNair Program on Identity ........................................................................ 107

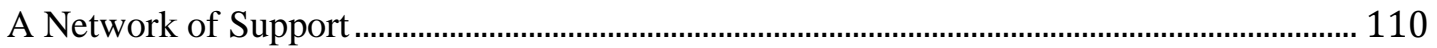

The Next Step for the McNair Scholars................................................................................. 111

Implications ............................................................................................................14

Future research .......................................................................................................117

Now that I know who I am, I find a greater sense of purpose........................................121

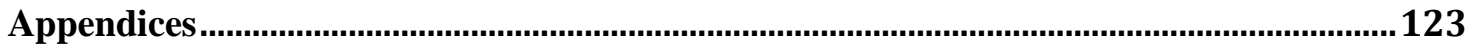

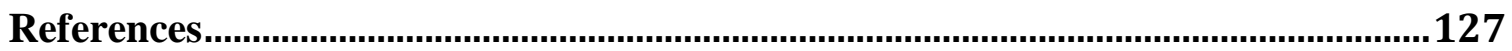




\section{List of tables}

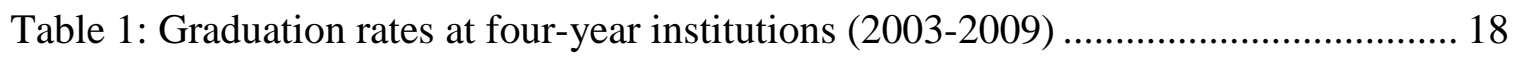

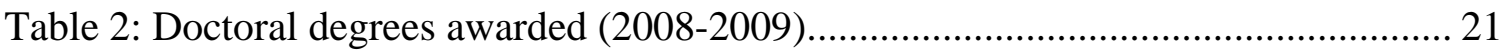

Table 3: Parental educational attainment (1989-2009) ................................................. 22

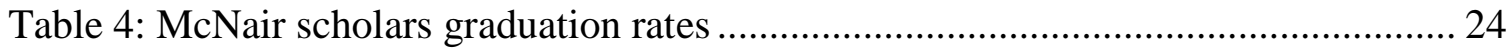

Table 5: McNair scholars gradaute school enrollment ............................................... 25 


\section{Chapter I}

When I left home, I left behind not only my family but also everything that I was familiar with. College was intimidating not because of the workload...that was the easy part. Interacting with peers and teachers who looked nothing like me, nor did they understand where I came from was the biggest challenge.

A diverse campus is goal of most four-year universities in America, however very few campuses have achieved such a goal. Looking at the overall student population, we see that in 2009 approximately $37.7 \%$ of students in public four-year universities were of a minority race (The Chronicle of Higher Education, 2011). Though this number has been rising steadily each year (1976- 13.4 \%, 1980 14.3\%, 1990- 18\%); the majorityminority ratio is still lopsided. A similar trend occurs at the graduate level as well, where $64.7 \%$ of all graduate students are of white, non-Hispanic ethnicity, $79 \%$ of all faculty are of white, non-Hispanic ethnicity.

A recent study done in the northeast found that the diversity of the faculty does not match that of the students (Hardy-Fanta \& Ransford, 2010), which is quite common amongst most universities. Looking at the university from that point of view can make the whole scene of higher education unwelcoming or maybe even threatening for minority college students; the lack of diversity amongst the faculty and staff play a significant role in the student's academic success in these college settings (Austin, 2002; Swail, Redd \& Perna, 2003). These students are forced to adapt and function in a place that does not even reflect their own culture and experiences. By first creating diversity at the top (i.e. Faculty), we start to create an environment where students feel like they are 
welcomed and understood. To achieve such a goal, we first need to get underrepresented students (i.e. minority or first-generation) into college settings, provide them the necessary training and credentials to become faculty; and increase the rates at which these students graduate and eventually get their doctorate degrees.

Based on my past and current experience of going through the graduate school process, this research was created to help understand minority and first generation student's (FGS) journey through post secondary education. Students from these populations have lower graduation rates and often do not even consider going to graduate school (Smedley, Myers, \& Harrell 1993). The Ronald E. McNair scholars program at West Virginia University (WVU) graduates approximately 90\% of all participants enrolled in the program and of those who graduate, more than $60 \%$ attend graduate school. The program recruits students from under represented backgrounds, which include: African-American, Hispanic, American Indian, Alaska-Native, Pacific Islander, Native Hawaiians as well as low income and first generation college students. The research will focus on the challenges they face in their undergraduate career, how they overcame them to reach the graduate level and the role that the McNair program played in their journey.

Intertwined with their experiences I shall reflect upon my own experiences going from undergraduate to graduate school and share my challenges (italicized font). Being minority and FGS, I recognize the challenges that these students face, I struggled to find out who I was, and if I was good enough to be on the same level as others in academia. Even now as a doctoral student, I constantly question why I am in higher education and do I really belong here. I find it ironic that my role as a McNair graduate assistant puts 
me in a mentor position; a person educating these students on what they should be doing to prepare to get into graduate school, how to conduct and write scholarly work, and ultimately how to make yourself a strong graduate student candidate is coming from the same person who barely made it into graduate school, me.

The WVU McNair scholars’ journey to graduate school, as was mine will be filled with many challenges and triumphs. The research will look at their experiences with the program and at their respected graduate school programs. The research enters the lives of WVU McNair scholars to provide an in depth look at their experiences and how the role of the McNair program in their journey.

\section{The Life of Ronald E. McNair}

Before I can describe the program, I must acknowledge the great man that Ronald E. McNair was, and how his legacy affects the program. Born on October 21, 1950 in Lake City, South Carolina; he shown an interest in not only education but also work ethic at an early age (The spirit lives on...A tribute to Dr. Ronald E. McNair, n.d.). Being African-American, he grew up during the times of the civil rights movement, and accomplishing what he did was a feat itself; he was able to graduate from Carver High School as valedictorian and eventually enroll at a four-year university. It was during his high school years when he developed a passion for physics and made a promise to himself that he would graduate with a doctoral degree within the next ten years of graduating from high school (The spirit lives on...A tribute to Dr. Ronald E. McNair,

n.d.). When he reflected upon his high school career at a college commencement speech he gave later on in life, he recalls being afraid and a fear of not knowing enough. He mentions the conversations he overhead of the great physics classes that students from 
the north got to take, and he wondered if he was "good enough" coming from a impoverished neighborhood in the south. That fear was erased during his undergraduate years and in 1971 he graduated with a Bachelors of Science Degree in Physics from North Carolina A \& T University, and enrolled in Massachusetts Institute of Technology’s (MIT) doctoral program in physics. He met his ten-year goal and graduated from MIT in 1971. However it is not his academic prowess that Dr. Ronald McNair became known for. Outside of the world of academia, Dr. McNair held a fifth degree black belt in Karate and was also an accomplished jazz-musician playing the saxophone. However his true dream and aspirations for life came along with the establishment of the NASA program. Selected in 1978 as an astronaut candidate for the NASA program, Dr. McNair became just the second African-American to fly into space. His life came to tragic end doing what everyone in his family and closest friends said he loved doing. On January 28, 1986, on board the Challenger shuttle, Dr. McNair and six crewmembers lost their lives. However his legacy lives on, and through the life that he has lived and his accomplishments paved the way for the Ronald E. McNair Post Baccalaureate program.

\section{The Ronald E. McNair Post Baccalaureate Program}

Historically since the 1960’s, America has made a push to make education attainable for all. Programs such as “TRiO”; allowed minority students and those from low income backgrounds have the opportunity to succeed at secondary, post-secondary, and at the higher education level. During the 1960's three programs were initially created: Upward Bound, Talent Search, and Student Support Services, which is where the name “TRiO” originates, paying tribute to the first three programs. After the death of Dr. 
Ronald E. McNair in 1986, amendments were made to the Higher Education Act of 1965, and with the help of the late Dr. Ronald E. McNair's family, the Ronald E. McNair post baccalaureate program was created. The very first McNair program was introduced in 1989(Grimmett, Bliss, \& Davis, 1998).

WVU started the Ronald E. McNair post baccalaureate program in 1999 when the university was awarded its first grant. Since then, the program has served approximately 12-15 students each school year. The programs goals as described in the most recent grant proposal are as follows:

- $80 \%$ of McNair participants will complete research and scholarly activities that will directly impact their educational progression each McNair program year

- 95\% of new participants served in each McNair Program academic year will attain a baccalaureate degree within (three) years

- $65 \%$ of bachelor's degree recipients will enroll in post baccalaureate program by the fall term immediately following completion of the Bachelors degree

- $40 \%$ of McNair participants will attain a doctoral degree within ten years of the attainment of the bachelors degree

-The 2007 WVU Ronald E. McNair Post Baccalaureate Achievement Program Abstract, 2007, pp. 7-8

To achieve these objectives, the program requires students to develop their own research project and present their findings at a national conference before the students graduate. 
To help guide the students during this process, students are paired with and mentored by a faculty member in a related field. Students may either choose a faculty mentor on their own, or they are assigned one based on their research interest. Together they develop a research project that the student will complete under the guidance and tutelage of a faculty mentor. Once paired with a faculty mentor students participate in a six-week summer research program that engages them in: research writing, data analysis, research methods, professional seminars, GRE test preparation, and graduate school campus visits. The summer research program is capped off when all students attend a national McNair conference to observe other McNair scholars present their research. The summer research program equips the scholars with the necessary tools and skills to carry out their proposed research over the next year.

Following the summer program, students continue their proposed research and also take a one-credit course in the following Fall and Spring term. The course provides students a space to receive one-on-one help with their research from the McNair staff and support from their fellow peers. In addition to writing up their research project, students refine their resume, curriculum vita, and graduate school personal statements as additional assignments for the class. The course serves two main purposes: the first is oversee the progress of the students throughout the year and provide support and assistance when necessary, and the second is to provide a common academic place for McNair scholars to grow closer without the stresses and demands of the outside environment.

With campus visits and conference presentations intertwined with the McNair program curriculum, students get to open their eyes to the rest of the world of academia. 
From campus visits they get guided tours of campuses, scheduled appointments with faculty, and meet other graduate students. From conference personations the students gain public speaking and presentation skills, and a chance to branch out and build networks with others in academic community.

It is not always academic rigor that the students engage in, throughout their time with the McNair program; students have to the opportunity to attend various cultural trips. These events offer students a chance to engage in activities that they may not have had the chance other wise. Past trips included: going to a Chinese orchestra performance, watching the Washington Wizards pro basketball game, or getting a tour of the Smithsonian museums in Washington D.C. These social and cultural opportunities give a glimpse of what society has to offer to a population who may not have had the opportunity or financial capabilities to do so; it also helps to remind the student to take time to unwind, relax, and take a break from the academic stresses they encounter throughout their undergraduate career.

Lastly students are provided with academic advising, tutoring, financial aid counseling, other research opportunities, laptop rentals, GRE training books, funding for travel, and other enrichment programs. Through these services and activities, these McNair scholars form a close-knit community amongst their peers, faculty and McNair staff.

By leveling the playing field, McNair scholars from low-income/first generation and, or traditionally under-represented groups are just as likely or more likely to persist to the doctoral degree as those who come from families where race is not 
an issue, income is not an issue and at least one parent has graduated from college.

-The 2007 WVU Ronald E. McNair Post Baccalaureate Achievement

Program Abstract, 2007, p. 12

\section{Falling Through the Cracks}

Affirmative action, open admissions, and the increase in financial aid paved the way in opening doors that were not available to minority students, and by 1975, approximately one-third of minority groups were in college (Edwards, 1993). These open doors eventually became revolving doors (1993), meaning students now had access to enter the university but were quickly exiting as fast as they were entering. Retention of these students became a major issue in colleges and universities around the nation.

Minority students, especially those from low-income families took courses that they could not engage in, these students lacked the necessary skills to succeed in the course. Not all students go through the same schooling process, and not all students have access to schools that are able to teach the fundamental skills needed for college. Fast forward to today and we see the effects of the No Child left Behind Act (NCLB) and how students lack even more of these basic skills because of all the pressure from standardized testing that forced out other essential skills required to live in a multicultural nation (Banks \& Park, 2010). Schools eventually become defined by the scores that their students achieve, and it is the schools which serve the ethnic minority and low-income who often do not have the resources who suffer. "Consequently, the NCLB Act is increasing rather than reducing the educational equity” (p. 388). Edwards (1993) said it 
best when describing the need for universities and colleges alike to bring these students (minority, low-income, FGS) up "to a level of competitiveness with those who had come with success as birthright” (p. 312).

To accommodate these challenges colleges and universities tested basic skills of students before allowing students into courses. Students were tested on math and reading skills so that they could be placed into the appropriate courses. Being placed into the appropriate courses was the first step for a student to be successful. Another factor contributing to the low level success of minority groups revolve around financial needs (Levine, 1993; Rodriguez, 2000). Being placed in the right courses and having money took a student only so far in college.

Too many of our students who come to our campuses lacking the skills and the confidence to succeed leave us exactly the way they came. (Edwards, 1993 p.

Edwards (1993) makes two interesting points about a lack of skills and lack of confidence. The question is why is this true? The public (or private) school can account for some these issues but certainly not all. It may be true that those FGS and minority students lack skills that others may have acquired at their respected schools. One could also attribute this lack of skills to the family background, as many of these students have family members who have not attained a college degree or even a high school diploma. In some cases these families may not even value education and that a job that pays is all you need to succeed in life. Up to this point, universities have provided the tools and skills necessary to thrive academically, meaning schools have tried to give minority and 
FGS the academic knowledge (i.e. testing skills, appropriate classes) but seems that approach did not work as effectively as they had hoped. One major factor was needed to be recognized, the students them selves.

No matter how far students left to go to college one thing they could never get away from is their culture. Within each minority group exists separate standards set by those of the group and those outside. For example, the discrepancies on views on education by the white majority and the Latino community often result in a clash between the two (Cuadraz, 1996; Espinsoa, 1995; Torres, Howard-Hamilton, \& Cooper, 2003). Cuadraz (1996) describes the movement from a minority populated community and how they are negatively treated in a primarily white environment, and hot the implicit values and beliefs that Latino’s from low socio economic backgrounds have does not fit within the higher education setting. This is not only true for Latinos, but for other minorities and even FGS alike. Trying to adopt new beliefs and values bought on by the college curriculum can be detrimental to the student's well being, which is why these students have to find a place that helps them to find the balance between the two.

\section{A Sense of Belonging}

After struggling through my freshman and sophomore year at college I finally found my niche in the college environment. My grades improved, I developed a genuine interest in research and academia, and even got involved in teaching. During this time, I also noticed that every time I left college and went back home I was treated differently. Most did not understand why I was so interested in research, nor did they approve of the way I spoke; saying that I used fancy words when speaking, and was becoming more and more "white". Although these people never said it out loud, I knew that they felt 
uncomfortable around me and was not happy with the person I was becoming. By the time I graduated I did not know who I was, at home I was one person and at college I was someone completely different, it seemed that I formed two completely different identities, and was forced to choose one or the other. Often times questioning who am I?

Identity is crucial to a student's success, not only in the classroom but outside of it as well. My own struggles are reflected in African-American, Latino, indigenous cultures, and FGS who speak in different languages (or dialects) in their home and school cultures (Kincheloe 2007); this is not referring to a different language (i.e. English in school, Spanish at home), but in regards to the word choice, sentence structure, etc. Being trapped in this environment can cause students to lose themselves in terms of who they are. It is human nature to adapt and evolve according to one's environment. The question is: What happened when a person is conflicted between two environments? These students fail to find a balance to meet the needs of both their culture in schools and the home culture, resulting in one suffering more than the other.

The curriculum although constantly changing needs to have an emphasis on selfdiscovery, a student's need to be comfortable about who they are, and everything they stand for. They go back and forth between various identities to see where they fit best. In worst case scenarios their grades, social life, as well as family life decline. They never seem to find a fit within college, and within this process of self-discovery, these students find themselves dropping out of school.

For minority students and FGS, identity is a constant struggle. A sense of community is needed for these minority and FGS to discover their identity. The gap 
between home and school culture needs to be narrowed. Students of minority backgrounds or who are FGS lack the support outside of the classroom. It is the university that needs to lend support to these students to help them achieve more socially and academically. The support for students comes in a variety of ways. For example numerous universities offer students support in the forms of financial aid, academic advising, health care, subject specific tutoring, career counseling, housing, etc. The list goes on and on, and each university have ways of supporting students, however even these services are sometimes not enough for minority and FGS to succeed.

Retention was and continues to be a major issue for all institutions of higher education. The doors have been opened and support services exist to serve all students. The last task is to keep these minority and FGS there long enough to reap its benefits (Edwards, 1993). Universities around the country have implemented various programs to keep minority and FGS at their respected universities. Clubs and organizations help bring these groups of students together under a common cause. Early transitions for freshmen as well as orientation days help serve these vulnerable populations and target them early on to prevent dropouts from happening. The academic and social integration into the college setting (Tinto, 1975) continues to be a challenge of all universities, especially since the increase of minority populations.

All that has been done to alleviate these issues around minority and FGS have made improvements along the way, but these populations are still struggling to compete in society when compared to their white majority counterparts. These students are still isolated and marginalized within the university setting. These students are often overlooked and overwhelmed by expectations set before them. The university has 
provided programs that serve to increase the tools and skills of minority and FGS that are necessary to succeed in college, but has come back with lack luster results. We must look at this problem from a deeper perspective and dwell into the underlying factors that help these students find a sense of belonging to help them excel at the social and academic level.

\section{Statement of the Problem}

The first step in keeping these students in the university and having them succeed and graduate is to change the environment. Universities and colleges can only do so much to be culturally competent and sensitive to the needs of minority as well as FGS. Students at historically Black colleges tend to get more out of the college experience. Not surprisingly at those colleges, the student's population is reflected in its faculty population, students feel like they belong, like faculty care, and they are amongst a community of peers which feel like a family (Palmer \& Gasman, 2008). A variety of reasons may contribute to this including: faculty share similar historical experiences with students, students are able to identify with one another, people for the most part the campus is filled with ethnic minority students or other reasons. In either scenario, a truly diverse university at both the student and faculty level create a safe environment conducive for learning that is welcoming, and supports all races and cultures.

Changing the face of academia to reflect a more diverse population is the ultimate

goal for the Ronald E. McNair post baccalaureate program. Finding reasons why students succeed and go on to graduate studies is essential in designing more programs to help narrow the education gap at the post-secondary level. Past research has used quantitative research methods to determine the satisfaction and effectiveness of the 
McNair program and specific components that were deemed effective (Grimmett, Bliss \& Davis, 1998), and factors in increasing graduate school preparation (Chatman 1994, Esler 1998, Wyre, 2011).

With the growing trend in qualitative research, studies now focus more on student's individual experiences. Qualitative research within the McNair community highlight experiences of scholars through the use of auto-ethnographies (Beal 2007), experiences and perceptions of McNair program members while in the program (Derk 2007, Gallagher-Trayhan 2010), experiences of McNair alumni at the faculty level (Ford 2011), reasons why McNair scholars go on to higher education and persist (Olive 2010, Baness, 2011), and McNair Scholar’s experiences within graduate school (Willison \& Gibson, 2011).

Individuals within a group can vary from one another, although they may share the same experiences and values, which really define us. It is the individual and their own identity construction that needs to be studied, therefore not only must research look at how services help a student but why it helps a student. Surveys and other forms of quantitative data scratch the surface of this issue, which why a qualitative approach needs to be used. Adding to past and current qualitative literature on minority and FGS, this research will look at the student's identity and how the WVU McNair program shapes it. The purpose of this study is to examine the McNair Scholars program at WVU and take an in depth look at the experiences of these scholars, and how the program plays a major role in their experience. 


\section{Research Questions}

To provide insight on this problem the following questions will help guide the research:

1.) How does the WVU McNair scholars program affect the student participant's identity?

2.) How do the services provided by the WVU McNair scholars program affect the student's sense of voice and space?

3.) Is there a transformation that takes place during or after the student's involvement in the program?

\section{Limitations}

This research will focus only on the WVU McNair scholars and their experiences with the program. There are currently 200 McNair programs in the United States, and although most programs are successful, the WVU program exceeds the national average in success rates (in terms of graduating and enrolling scholars into graduate school). Looking at all McNair programs nationwide, approximately 53\% enrolled in graduate school immediately following their graduation in the 2006-2007 school year (U.S. Department of Education, 2012). The experiences of the WVU McNair scholars cannot be used to generalize across the population of all McNair scholars because it is unique to WVU, however it does provide a glimpse of reasons why this program in particular is effective.

I have been involved with the McNair scholars program at WVU for the past three years. Over that time I have built relationships with the staff and students that have come through the program. Though I am not a McNair scholar, I have always been 
treated with dignity and respect and accepted as one of their own. This unique researcher role of being an “outsider” (non-McNair scholar) and “insider” (WVU McNair graduate assistant) establishes a deeper rapport with the students therefore enhancing the quality of the interviews. At the same time, this may also serve as a limitation since students may feel pressured to provide positive feedback on the program because of my role as a staff member. 


\section{Chapter II}

College was never talked about in our household while growing up. Not one of us had aspirations to go on. I cannot even remember planning my life after high school. I assumed like the rest of my immediate family I would work or join the military. I once asked my dad about college and why he never went. He told me that he did attend college for a little while and said he realized college was not for him, and dropped out to work at a local company. I never questioned why my dad dropped out because college was only for the rich or incredibly smart population... I belonged to neither.

\section{Minority and First generation Students in Higher Education}

Within the United States, schools typically force immigrant and minority students to conform to the dominant culture's norms and behaviors (Aguirre \& Turner, 2001; Graham, 2005), which is why it is no secret that minority students perform poorly in predominantly white colleges than the others. African-Americans and non-Asian minority have lower GPA's, have higher attrition rates, are less likely to graduate (within five years), and enroll in graduate schools at lower rates (Smedley, Myers, \& Harrell 1993). Barriers such as socioeconomic status, stereotypes, and under preparation all contribute to low participating numbers in higher education for Latina students (Rodriguez, GuidoDiBrito, Torres, \& Talbot, 2000). Overall these minority students are not academically prepared or even ready for college (Martinez \& Klopott, 2005). The disadvantages and struggles that plagued minority generations in the past, are being passed down, so that the children of disadvantaged parents are still not likely to have educational success (Attewell \& Lavin, 2007). 
With good intentions, all colleges and universities in the U.S. welcomed minority students' with open arms. In 1976, white students made up 82.6\% of all degree-granting institutions, by 2009 that percent dropped to 62.3\% (National Center for Education Statistics, 2012). Even in the past decade, college enrollment growth for minorities was far better than whites (Chronicle of Higher Education, 2011). Although, the minority population increased, the graduation rates for minority students did not make progress (Table 1).

Table 1

\begin{tabular}{lr}
\hline $\begin{array}{l}\text { Graduation rates at four-year } \\
\text { institutions (2003-2009) }\end{array}$ \\
\hline All & $57.4 \%$ \\
\hline Men & $54.8 \%$ \\
\hline Women & $59.6 \%$ \\
\hline American Indian & $38.4 \%$ \\
\hline Asian & $68.0 \%$ \\
\hline Black & $39.1 \%$ \\
\hline Hispanic & $48.7 \%$ \\
\hline White & $60.9 \%$ \\
\hline Foreign & $53.3 \%$ \\
\hline
\end{tabular}

- The Chronicle of Higher Education, 2011

Most of the minority groups (with the exception of Asian) graduate from college well below the national average. Students from minority come to college without the necessary skills and trainings to take on college course, in the 2007-2008 school year, 
more than $80 \%$ of the minority population enrolled in at least one remedial course in reading, writing, or math (Chronicle of Higher Education, 2011). These factors are part of the reason why minority students do not graduate from college is because they are already two steps back behind everyone else. This goes to show that "college access did not erase [the] disadvantage for everyone” (Attewell \& Lavin, 2007 p B15).

Those coming from minority backgrounds are not the only ones at risk; FGS also suffer from the same problems. First off, these students are older when they first enter college, have lower incomes, and tend to be married when compared to the majority college population (Nunez \& Cuccaro-Alamin, 1998; Choy, 2001). In the Fall 2010 term, they accounted for $20.6 \%$ of the freshmen population (The Chronicle of Higher Education, 2011). The lack of information from family and relatives on post-secondary school leaves FGS academically less prepared (Hsiao, 1992; Thayer, 2000), and at-risk for attrition (Horn, 1998; Ishitani, 2006; Nunez \& Cuccaro-Alamin 1998). Coming from a family background where college is not part of the norm, students have difficulty picturing themselves going to college. They look around and find no role models or mentors to help them realize that college is a viable option. In some cases, families and friends may even discourage FGS from going to college, thus contributing to the doubts and fears of college (Striplin, 1999). Like most college students, those FGS wanted a place to find friends, gain support and be somewhere where they could feel comfortable (Hsiao, 1992).

To summarize, minority and FGS lack the knowledge about college preparation, attendance and post-graduation plans (Vargas, 2004). To graduate from a four-year university is the first objective of the WVU McNair Scholars program. Getting WVU 
students to succeed at this level is only the beginning step in their journey as a McNair scholar.

\section{A Tough Road Ahead}

Just because one gets accepted into a doctoral program does not necessarily mean that they will obtain that doctoral degree. Students who come from this background already have the odds stacked against them, and to make matters worst, only half of all doctoral students graduate (Lovitts \& Nelson 2000). For these students, graduate school is not even on the radar, or even a logical choice (Cole \& Barber, 2003); in fact only 19.1\% of college freshmen hoped to achieve a Ph.D. or Ed.D. (The Chronicle of Higher Education, 2011).

In the 2008-2009 school years, 67,716 doctoral degrees were awarded, and only $1.7 \%$ of the entire U.S. population has a doctorate degree (The Chronicle of Higher Education, 2011). Table 2 is a breakdown by ethnic group and the number of degrees awarded within each group. Even at the doctoral level, White students are outperforming minority groups. Often times, the gap may seem insignificant, but when non-residents (foreign students) are accounted for, we see that underrepresented minorities like American Indians, Asian/Pacific Islander, Black, and Hispanic groups still struggle to obtain doctoral degrees.

Generally FGS have low degree aspirations (Nunez \& Cuccaro-Alamin, 1998) putting doctoral studies beyond the grasps of reality. The current trend of doctoral recipients indicates that less FGS are obtaining doctorate degrees, and point to family educational attainment as an influential factor (National Academy of Science, 1997). 
Table 2

\begin{tabular}{|c|c|c|}
\hline Race & $\begin{array}{l}\text { Percentage of Total } \\
\text { Doctorates }\end{array}$ & Doctorates \\
\hline American Indian & $0 \%$ & 332 \\
\hline Asian/Pacific Islander ${ }^{1}$ & $6 \%$ & 3,875 \\
\hline Black & $7 \%$ & 4,434 \\
\hline Hispanic & $4 \%$ & 2,540 \\
\hline White & $59 \%$ & 39,648 \\
\hline Nonresident Foreign & $25 \%$ & 16,887 \\
\hline
\end{tabular}

- The Chronicle of Higher Education, 2011

Being alone in a doctoral program without support from friends, family and colleagues presents a daunting task, this lack of social support from both the non-academic (i.e. family) and academic (i.e. faculty advisors) are common reasons for these students to drop out (National Academy of Science, 1997). Those coming from families who have experience with an advanced degree obtain doctorate degrees at a much higher rate than other populations (Table 3). Trying to balance the stresses of doctoral studies, financial hardship, and lack of psychosocial support can take its toll on these students. Getting through the undergraduate program was already a reason to celebrate; now these students are tasked with surviving in a whole new world of academia.

1 The Asian race has a much higher doctoral degree attainment rate, which is why they are excluded from the underrepresented minority group. However in this case, the organization combined Asian and Pacific Islander, which suggests that the Pacific Islander race is lowering the total percentage. 
Table 3

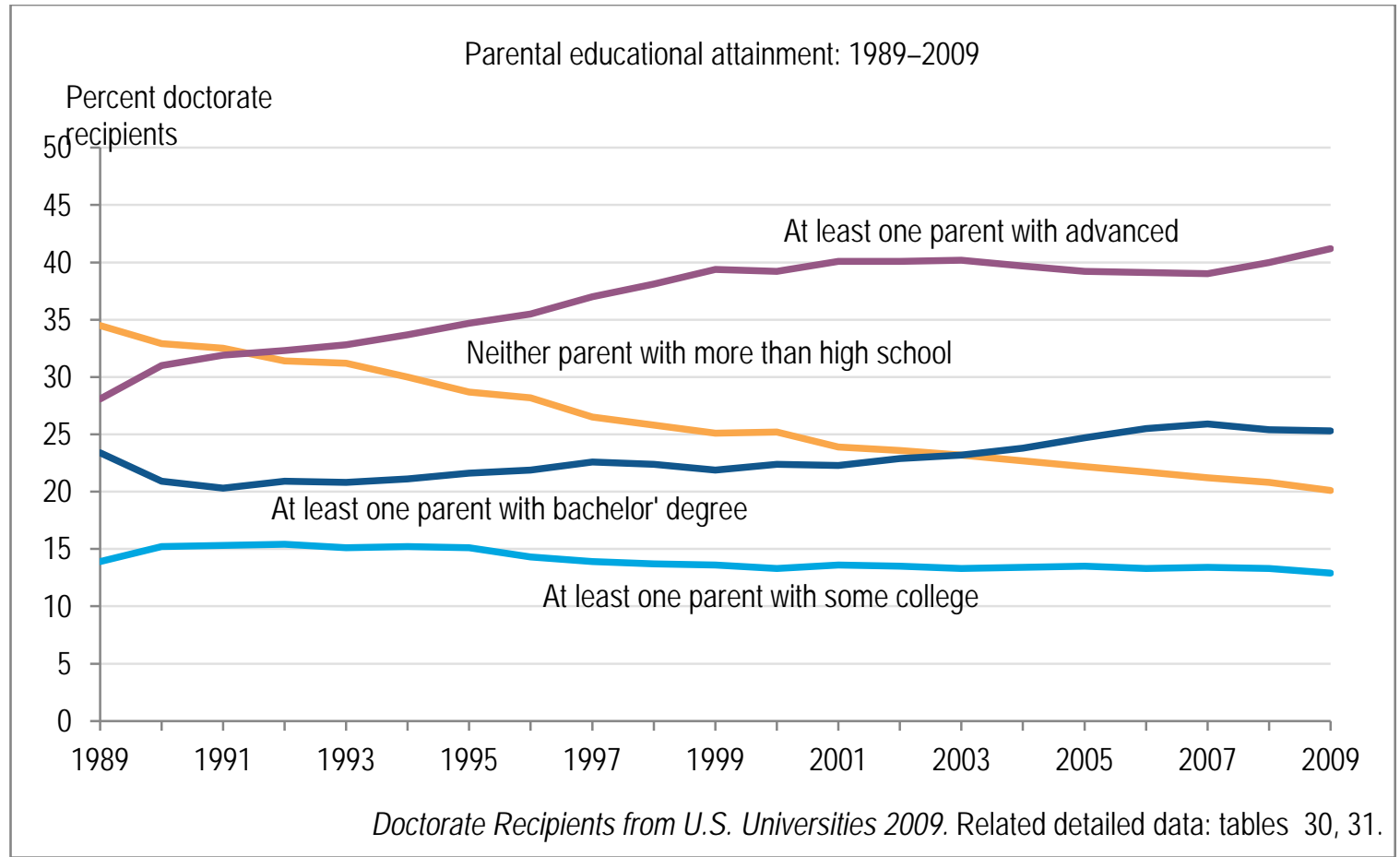

- National Science Foundation, 2007

\section{The Path to Success}

Even though it occurred over five years ago I could still recall that day...I picked up the school newspaper along my way to school, a weekly ritual to keep me entertained. In the student opinion section I could not believe what was being printed. A student at the school was claiming the university to be unfair, the student claims that because a few sections of an English course was reserved for minority and first generation students, it was unfair to other students...to summarize the student article, minority and first generation students do not need special sections of college courses, nor will the presence of these programs boost the success of students from this population.

Students coming from the dominant culture may not always understand why programs and services exist to help the at-risk population (in this case the students of 
minority or FGS background). These students from dominant culture understand the history between majority and minority groups, as well the meaning of affirmative action, but are still perplexed about why these students need the extra help.

Edwards (1993) expressed the need of the three S's (structure, support, and service) in higher education to address the concerns of this at-risk population. Providing students with a stern structure that challenges their intellect in a safe environment will allow the student to grow. Refusing to offer alternate criteria, the school refuses to dilute their academic experience (1993). Although these students seem academically less prepared, we cannot use this as an excuse to make work less challenging.

Creating a structure this rigid has to come with a network of support. These students need mentors in their lives, mentors that will provide the psychosocial support (Ishiyama, 2007) to help them thrive in an academic community. Mentors within the faculty and staff rankings can help the student get adjusted and feel a part of the university. Students also need support in terms of being recognized as individuals on campus and amongst the academic community. Having their voices heard amongst the community empowers them to find an identity in academia. A sense of belonging on the student's part creates a community environment that nurtures success.

Lastly support services help to retain students long enough so that they can benefit from everything the university has to offer (Edwards 1993). Programs such as multicultural learning communities and cultural centers help students learn more about their culture (Capello, 1994) and to establish a voice in the university, creating a sense of belonging for these students (Jehangir, 2009). Even if these programs do exist in the 
university setting, FGS often overlook these services because they feel they do not qualify or that the services are geared only toward minority students. Having programs that are structured to challenge the student while being sensitive to their needs by lending support is a key getting these students to excel on their own.

\section{Signs of Change}

McNair scholars already show promise at the undergraduate level, the latest report on their achievements show that over $90 \%$ graduate with a Bachelor's degree within four years of participating in the program (Table 4), surpassing the national graduation rate (57.4\%) after two years of participating in the program. At the undergraduate level, the McNair program is effective in supporting student graduation rates.

Table 4

\begin{tabular}{lccccc} 
& \multicolumn{5}{c}{ Year of active participation } \\
\cline { 2 - 5 } & $1997-98$ & $1998-99$ & $1999-00$ & $2000-01$ & $2001-02$ \\
\hline Number of records & 2,203 & 3,121 & 3,338 & 3,877 & 4,012 \\
When bachelor's degree was earned & & & & & \\
In year of program participation & $35.9^{\mathrm{a}}$ & $38.7 \mathrm{a}$ & 23.8 & 23.4 & 21.0 \\
One year later & $54.3^{\mathrm{a}}$ & 70.0 & 58.7 & 63.0 & $\dagger$ \\
Two years later & 86.9 & 86.6 & 84.5 & $\dagger$ & $\dagger$ \\
Three years later & 92.1 & 93.0 & $\dagger$ & $\dagger$ & $\dagger$ \\
Four years later & 94.8 & $\dagger$ & $\dagger$ & $\dagger$ & $\dagger$ \\
\hline
\end{tabular}

aFor reporting years 1997-99, "has not yet earned a BA" was not an option for degree status. Because of this, this variable has a high nonresponse rate ranging from 45.6 to 64.1 percent for the active participants in those years. We assume that the missing cases for this variable indicate those who had not yet earned a bachelor's degree and include them in the denominator when calculating these percentages.

†Not applicable; not enough time has passed to determine cell value.

NOTE: Percentages reported include bachelor's degrees or higher because a bachelor's degree is assumed if a more advanced degree is reported and a bachelor's degree is not. Percentages reported are of the total number of active participants in each year and exclude missing cases from the denominator ( $<10 \%$ are missing for all years); as such, the totals here may differ from totals presented in other tables.

SOURCE: Data from the program files of the U.S. Department of Education, Office of Federal TRIO Programs, Ronald E. McNair Postbaccalaureate Achievement Program, Annual Performance Reports.

-Seburn, Chan, and Kirshtein, 2005, p. 24

Once students graduate, McNair scholars get into graduate school at higher rates than non-McNair scholars (Seburn et. al, 2005). During the span of four years, there has been 
an increase of approximately $16 \%$ of McNair scholars enrolling in graduate school immediately after graduating with their bachelor's degree (Table 5). It should be noted that these numbers could potentially be higher because this statistic only takes into account those students who immediately enroll in a graduate program. Students who choose to take a year off and enroll in graduate school at later dates are not accounted for. Inconsistent statistics (percentages fluctuate between 15\%-47\%) between each year during the period of 1997 and 2002 suggest that McNair scholars are taking time off before enrolling in graduate school (Seburn et. al, 2005).

\section{Table 5}

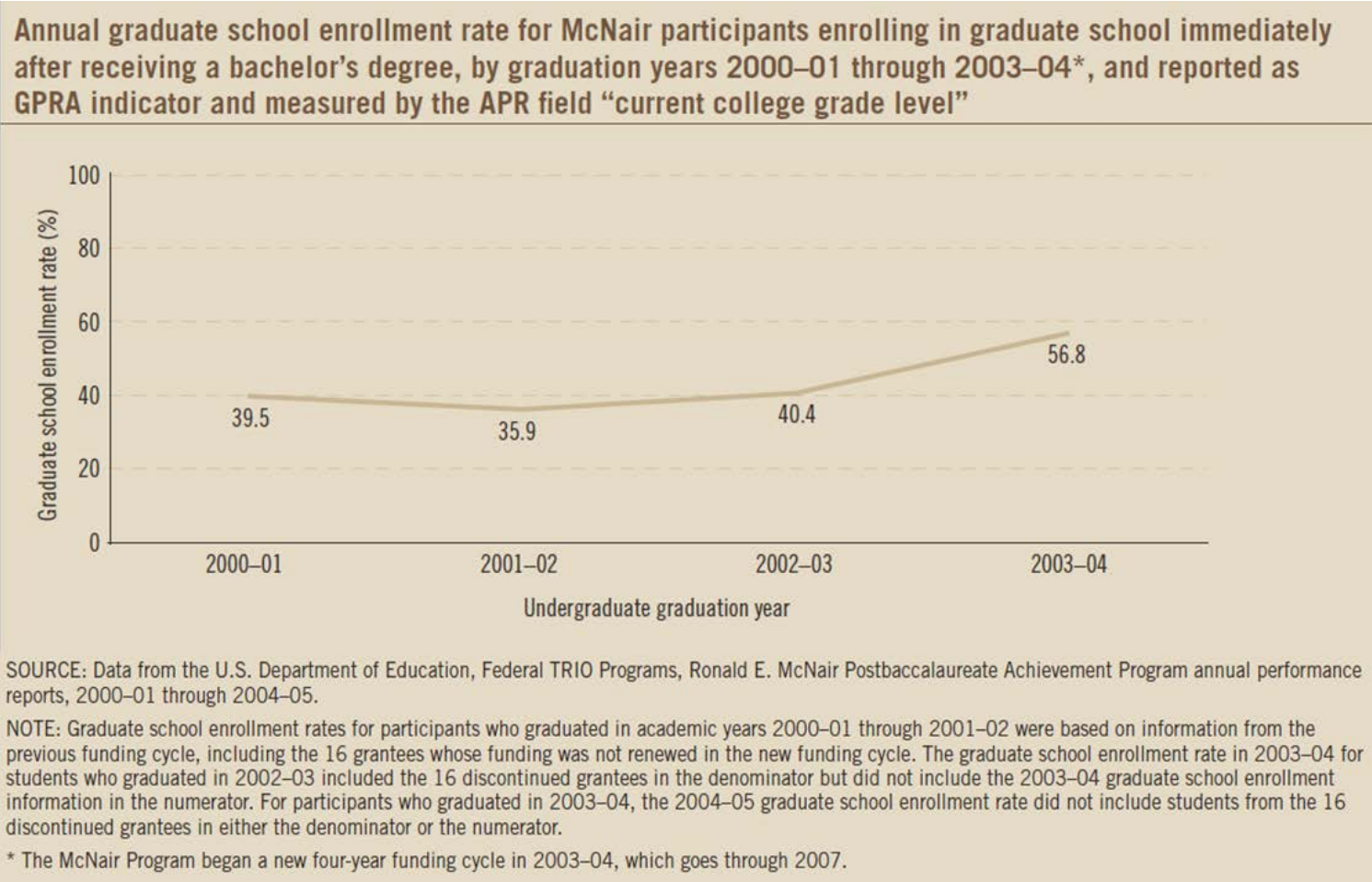

- U.S. Department of Education, 2007, p. 5 
Even though all McNair programs vary from one another, the U.S. Department of Education (2012) speficies that:

All McNair projects must provide the following activities: opportunities for research or other scholarly activities; summer internships; seminars and other educational activities designed to prepare students for doctoral study; tutoring; academic counseling; and activities designed to assist students participating in the project in securing admission to and financial assistance for enrollment in graduate programs. McNair projects may also provide the following additional activities: education or counseling services designed to improve financial and economic literacy of students; mentoring programs involving faculty members at institutions of higher education or students, or any combination of such persons; and exposure to cultural activities.

McNair students found the services of their program "somewhat helpful” when measuring their perceptions of the service (McCoy, Wilkinson, \& Jackson, 2008). The services offered by the McNair program equip the students with the needed training and expereince to make them ideal candiates for graduate school, as shown by their graduate school acceptance rates.

Particular services such as publishing research and working with/on faculty research were some of the avtivities that McNair scholars found most useful or helpful (McCoy et. al, 2008). These could also be as activities that directly involve the student in academia. Getting the chance to publish research, helps authenticize or legitimize the 
student's acadmic efforts and abilities. Working with a faculty member (one that is already accepted into academia) enhances that student's sense of belonging in academia.

Structure, support and service are common practices that generate success amongst minority and low-income FGS population (Edwards, 1993; Martinez \& Klopott, 2005). The curriculum of the McNair program is rooted in these practices. The program challenges the students to follow the footsteps of Dr. Ronald E. McNair, to pursue a doctorate degree while providing the students with the support and services they need in a highly structured environment. However, once students graduate they are left to take what they learned in McNair and venture out on their own. Even though these students enter graduate school at higher rates, they persist at the same rates as non-McNair scholars (Seburn et. al, 2005). This goes to show that students possess the skills, training, and accomplishments, which on paper make them look like an ideal graduate student, but in reality do not have the internal motivation to complete the program. The underlying question is: Why are McNair scholars, with all the training and support they receive, still struggling to stay in graduate school? The researcher took an in-depth look at how the McNair program is affecting the scholar's identities.

\section{Critical pedagogy as a Theoretical Framework}

I was asked to apply for the McNair Scholars program as an undergraduate. At first I thought what a wonderful opportunity it would be, but I thought about it more and more I convinced myself that I realistically could not (or would not) ever get a doctoral degree. Now in my doctoral program, I look back at the moment trying to recall why I choose not to apply. The answer was quite simple, I really did not know anything about graduate school, I knew no one who went to graduate school, and I never felt that anyone wanted 
me to go to graduate school. No matter how much skills I would gain as a researcher, experience presenting at conferences, or being paired with a faculty mentor, I just could not envision seeing myself as a doctoral student.

Many students who are eligible for the Ronald E. McNair Scholars program come from socially isolated and marginalized populations within the university. As demonstrated earlier, these students have been alienated from the university and subjected to the dominant culture; and although improvements have been made over the years, the statistics on them still send out a plea for help. These students wander through college without ever knowing who they are, or where they belong. Services such as tutoring, remedial courses, student services, advising, and writing centers all help to give the students the tools and skills needed to succeed, and yet statistics stated earlier still say suggest sub par performance in all levels of higher education.

To understand what these students go through, researchers must first understand who they are. Giving them the tools and skills will only take students to a certain point, students need to first understand who they are, reasons they are in college, and reasons they want to go on to graduate school. During this process, students are given the assistance to discover a space that is accepting of their history, culture, and individuality. In this sense, critical pedagogy is a useful theoretical framework to guide this study.

Critical pedagogy explains how audience, voice, power, and evaluation work together to construct relationships at the individual (teacher-students) and at the communal level (institution-society) (Giroux, 1994). To help understand how these students see themselves within the university, we must explore the cultural politics of 
schooling, where cultural politics refer to: the power relations between individuals and society, social practices (Kincheloe, 2007) and "privileging forms of knowledge that support a specific vision of past, present and future” (McLaren, 1995 p. 30). Critical pedagogy invites marginalized voices and allows them to "consider, evaluate, apply, reflect, upon and make connections between theoretical positions about...their own lived experiences” (Jehangir, 2008, p. 34). By bringing fourth their voices, students feel that their experiences are recognized and they belong in the academic community. Through critical reflection, students become aware and discover not only who they are, but also who they can become. By exposing the forces that block them from accomplishing this, students engage in praxis, and in the process transform their identity.

Using a critical pedagogy approach, the research uses the notion of space, voice, and identity to interpret the WVU McNair Scholar's on their journey to find a place within academia and illustrate how these notions are influenced by their culture, history, and view of their relationships with the communities that surround them.

\section{Space and Place}

Space is purposely created to aid students' learning experiences. When space is filled with life it becomes place (Callejo-Perez, Fain, \& Slater, 2004). Place is constantly being effected by those who are apart of it. A person's history, culture, perceived roles, and experiences are intertwined with place. It helps guide the students place in the world and "their relative proximity to power" (Jehangir, 2008, p. 34). The goal of space is to establish a community (Callejo-Perez et. al. 2004), and knowledge develops because of conversations that take place within communities (Miller, 1990). A community is developed once individuals feel safe and is able to communicate in a deep and authentic 
manner (Bickford \& Wright, 2006). Space provides the framework for the development of relationships and knowledge where individuals find meaning in themselves; it is a result of the social translation, transformation and experience that creates a meaningful space (Soja, 1989). The concepts of space and place describe everything that is purposely created by the McNair scholars program that effects the students overall learning experience.

\section{Voice}

The notion of voice is a complex term that encompasses a lot of definitions, which provide reasons and meanings to a student's overall learning experience. Aronowitz (1991) demonstrates that voice is integral in the student's learning experience:

Voice represents forms of self- and social representation that mediate and produce wider structures of meaning, experience, and history. "Voice” refers to the ways in which students produce meaning through various subject positions that are available to them in the wider society....[voice] provides students with the experience language, histories and stories that construct the subject positions that they use to give meaning to their lives. (Aronowitz, 1991, p. 100)

With a voice, students are able to see themselves as a part of the learning experience, rather then being objects of history (1991). It enables students to give meaning and validate to who they are, and how they fit in amongst society. When silenced communities find their voice and are heard, they are able to use this newfound power to begin taking control of their lives (Belenky, Clinchy, Goldberger \& Traule, 1986; Freire, 1993; Gilligan, 1982). Voice can take on multiple forms of representations that include 
auditory or tangible forms. As long as a voice is heard, whether it's in text or by ear it can give meaning to all. In this study using the notion of voice in this way will help to give meaning to McNair scholar's experiences and identity formation.

\section{Identity}

Kincheloe (as cited Pinar et al. 2004, p. 644 ) argues that the minority population has constantly received the short end of the stick, and that the oppressed population needs to refuse to accept the history written in texts and find they own way into their "official story.” This could be a typical experience of a minority student in high school. You want to tell this person that they should continue their education at the risk of losing their cultural identity and background. How would they fare in college? Students from minority backgrounds are coming into the university already filled with fears and doubts about the university setting. Already confused on what information is accurate and what is not, a student is again faced with the task of listening to mainly white male professors (Fordham \& Ogbu,1986).

Growing up in an African-American, Hispanic, American-Indian or a Native Hawaiian culture, a person of white ethnicity is not the most trust-worthy figure. With all the history of racism, hatred, marginalization, and isolation between majority and minority groups, it takes a lot to build trust and understanding between these groups. When others surround students who do not physically look like them, the hidden tension between the groups force separation. For minority and FGS, this usually means that they are left out of the academic setting, socially isolated and forced to adapt a new culture (Smedley et. al. 1993, Rendon 1994). 
Understanding the curriculum as political text and racial text provides an in depth look at how the curriculum shapes a person's identity. McLaren (1991) expresses the concern of the schools role in shaping the student's identity and proposes the following to be associated with critical pedagogy: all diverse cultural realities need to have a voice; choices need be seen as social practices; distinguish cultural choices as liberating or oppressive, and freedom needs to become something that needs to be won within discourse. In college settings, students from diverse backgrounds are often forced into joining clubs and organizations that share similar interests. With the intent to make these students comfortable within the college setting, it can sometimes have the opposite effect, separating and isolating them from the rest of the university and being confined to their own club/organization office space. Finding a way to include and support students into the college environment will help legitimize their college experience and gain an identity within the academic setting. If the college curriculum can become sensitive and relevant to the identity formation of its students, a student will be able to find their "true self" and not forced to become someone they are not. The research question posed earlier, How does the WVU McNair scholars program affect the student participant's identity?, guides the inquiry in looking at internal factors that are often overlooked within McNair scholars. Studying the identity development of these WVU McNair scholars will provide an insight to their experiences with the WVU McNair program. The following chapter introduces the various factors in identity development amongst this diverse population. 


\section{Chapter III}

\section{Identity Development}

Eh! How come you sound funny? You turning haole heh?... A lot of people back home used to describe me in this term, haole. It's a term I hated growing up, haole meant a white person, so people back home said I was turning white. This had nothing to do with my skin color, but mainly due to how I was spoke, my educational background, and overall mannerisms. I hated being called a haole, and I did everything I could to ensure that I was not "becoming haole". I constantly asked myself: Am I becoming haole? And if I was why did it bother me? Were my academic achievements forcing me to become someone I am not?

\section{Discovering Who I Am}

"Who am I?” and “Who am I becoming?” are common questions amongst students during their undergraduate and even graduate career especially for McNair scholars. Immersed in a culture of higher education, where everyone in the program is expected to get a Ph.D. is a culture shock, and even more so for McNair scholars who come from underprivileged or disadvantaged backgrounds.

Identity encompasses many features and aspects of an individual. Identity refers to how people view themselves in terms of their race, ethnicity, gender, place, and perceived role in society. As mentioned earlier, students need to discover their own sense of belonging within the university setting. To understand how the WVU McNair program affects the scholars, the research needs to understand the identity development within these populations. 
Most identity theories stem from the work of Erickson (1968), which state that individuals experience a conflict with their identity during their late adolescent years, and how they resolve this conflict establishes their identity. Major contributions to identity development of college students are attributed to Chickering and Reisser $(1969,1993)$ who developed the seven vectors of identity development which include: developing competence, managing emotions, moving through autonomy toward interdependence, developing mature interpersonal relationships, establishing identity, developing purpose, and developing integrity. This approach of identity development has been used widely by faculty and administration to foster the development of college students. The problem with this approach is that it is largely based on the development of white male students (Chickering \& Reisser, 1993; Torres et al., 2003). It does not take into account the other influences on student's lives, which may include: cultural values, history of oppression and even one's sexual orientation. The way higher education institutions approach identity developments can either be detrimental or beneficial for the student's college experiences. By assuming all college students go through the same developmental stages, universities have already failed the needs of all students, especially those from minority backgrounds.

\section{Identity Development amongst African-Americans}

To begin to recognize how minority groups such as African-Americans develop their identity, it is important to first recognize their history within the United States and the racism that existed between African-Americans and Whites (Torres et. al. 2003). From the beginning African-Americans have been denied access into the university setting (Anderson, 2002), and have only been granted access after significant events such 
as the Brown v. Board of Education and social movements like the civil rights movement which allowed many African-Americans, as well as other ethnic minorities, to enroll in White colleges (Torres et. al. 2003).

Cross (1971) used the French term nigrescence, to describe the identity development stages where "Black people who undergo a metamorphosis from identification with whiteness to identification with blackness and beyond" (Nigrescence, 2010, para. 1). Incorporating the social and cultural historical changes that occurred between 1971-1995, Cross' (1995) revised nigrescence theory consist of five stages that African-Americans go through. The first stage (pre-encounter) consists of uncertain personal attitudes about being Black. Individuals in this stage do not necessarily hate being black, but they start to have conflicting views about their race. Individuals may prefer the dominant values of white culture, have superficial interests in Blacks, or see race as a social stigma (Torres et al. 2003). The second stage (encounter) is when the individual starts to find faults within personal views and they start to feel guilt and shame for adopting previous worldviews. This causes a shift toward nigrescence (Cross, 1995), and the strong emotion felt transition them into the third stage (immersion-emersion). The guilt and shame felt in the previous stage starts to shift toward a sense of pride for returning to and adopting the black identity that was once rejected. Once they have found a healthy relationship with themselves and identity, they move to stage four (internalization), where they are now able to internalize their identity, Cross (1995) describes three basic functions during this time:

(a) to defend and protect a person from psychological insults that stem from having to live in a racist society, (b) to provide a sense of belonging and social 
anchorage, and (c) to provide a foundation or point of departure for carrying out transactions with people, cultures, and human situations beyond the world of Blackness (p. 113).

The fifth and final stage is blended with the fourth stage and is described as a reiteration of activities of the fourth stage (Cross, 1991; Torres et. al. 2003). The developmental stages proposed are not concrete levels that Blacks may go through, often they may drop down to lower levels or even at times skip a level. Those whose experiences with Whites are too painful or have an overarching hate toward them often persist within the third level and may sometimes drop to previous development stages (Torres et. al. 2003).

\section{Identity Development amongst American Indians}

American Indians (Deloria \& Wildcat, 2001; LaFromboise, Heyle, and Ozer, 1990) values and concerns are based on the responsibility to the family and friends, tribal identification, and the betterment of the group. The cultural values of these people have a direct conflict and goes against dominant culture values which include: "individualism, competitiveness and amassing property” (Torres et. al. 2003, p 49). Education is a process of examples and experience and therefore elders within the group are the best examples of the end product of education (Deloria \& Wildcat, 2001). The work of LaFromboise et al. (1990) provides five categories (Traditional, Transnational, Marginal, Assimilated, and Bicultural) of American Indian identities. These are presented as categories and not developmental stages, therefore they seek to show what American Indians may be experiencing within each category, and the goal may (or may not) be to move between categories to reach a desired goal. The category Traditional describe American Indians who speak their native tongue, know little English, and follow the 
traditions set by past generations. Included in the Transnational category are those that are caught in-between; they are able to speak their native tongue and English, however they are not fully convinced that they can immerse themselves in the dominant culture but yet they question the traditions of their own American Indian culture. In the Marginal category "these people are defensively Indian, but are unable, because of their ethnicity, to live the cultural heritage of their tribal group or to identify with the dominant problems" (LaFromboise, et. al. 1990, p. 638). Those that have already been accepted and adopted the dominant culture values are part of the Assimilated category. The last category Bicultural, is most similar to the fourth and fifth stages of Cross’(1995) nigrescence theory of African American identity development. Those American Indians in the Bicultural category are accepted by the dominant culture, and have strong connections to their tribal roots. These American Indians can seamlessly move between the culture and values of both the dominant culture and their tribal culture finding a balance between the two.

\section{Identity Development amongst Latino/Latina}

The term Latino is very broad and general. It represents people who trace their lineage back to Central or Latin America, and some Caribbean countries (Torres et al. 2003). To understand their identity development, research must understand these peoples relationship with the United States and their countries in which they originated from. To summarize the historical and societal issues that contributes most to their identity development deals with the land boundaries and immigration laws most influenced their relationships with the United States (2003). Torres (1999) proposes a model to help 
understand identity development amongst Latinos. The model identifies four orientations in which the Latino population experience:

The first is Bicultural orientation, which indicates a comfort level with both cultures. The second is a Latino/Hispanic Orientation, which indicates greater comfort with the culture of origin. The third is an Anglo Orientation, which indicates a greater comfort with the majority culture. And finally the Marginal Orientation indicates discomfort with both cultures and may indicate conflict within the individual. (Torres, 2003, p. 533).

This model did not explain the process of choosing each orientation, therefore a later study (Torres, 2003) found two overarching categories (situating identity and influences on change) which contribute to identity development. Each category was influenced by certain conditions; situating identity took into account the environment that they grew up in (i.e. was it diverse or primarily white), family influence and generational status, and self-perceptions of status in society; and influences on change looked individual's own conflict with their culture and changes their experiences within the environment. It should be noted that the term Latino and Hispanic is often used interchangeably, and sometimes individuals from these populations may even use the term Chicano as their identity. The distinctions between each group are very complex; this research does not try to differentiate between all terms, but recognizes that there are differences amongst each. 


\section{Identity Development amongst Asian-Americans}

Like the Latino population, the term Asian American includes a vast number of different ethnicities. Because of this, research has been limited, and although Kim's (1981, 2001) theory was primarily focused on Japanese women, it is generally applied to all Asian-Americans (Torres et. al. 2003). There are five stages; the first stage is ethnic awareness, where the individual first learns about his or her ethnic background. The second stage is white identification, where individuals like other minority groups mentioned earlier, start to internalize dominant cultural values and start to separate from the other Asian Americans. When Asian Americans start to realize that they are the minority, they start to rid themselves of dominant culture values, which are the beginnings of the third stage. The fourth stage, Redirection to Asian American consciousness involves identifying more and more with Asian Americans, these individuals will start to attend more ethnic events for Asians and take a vested interest in their culture. During this time, like African-Americans, Asian Americans may develop hate toward the dominant culture. The final stage, incorporation, occurs when Asian Americans are able to find that balance between who they are and their relationship to society, they are able to accept other racial groups and do not need to choose between their Asian American identity and dominant culture values.

\section{No Model Fits All}

To assume that all ethnic minorities go through the same identity development model, would be committing the same offense as saying all Asians look alike, or all Blacks look alike. Just because a person identifies with one identity does not mean that their social, political and historical experiences are the same. Racial or ethnic identity 
development theories provide only one part of that person's identity. Besides race, there are six other factors that may contribute to a person's identity development, these include: social class, gender, religion, geographic region, and abilities/disabilities (McEwen, 1996). Although not as clear as the racial theories presented, the following help to show that race is only a small part of a person's identity development.

When looking at African-Americans, Vandiver (as cited in Torres et al., 2003 p.42) highlights three internalized identities: Black nationalist, biculturalist, and multiculturalist. The latter two, biculturalist and multiculturalist describe those whose identities are influenced by more than one ethnicity (biculturalist) and those whose identities are influenced by more than one cultural perspective (multiculturalist). Alexander (2011) describes his own struggles as a gay African-American male in academia, on reflecting on his blackness he writes:

This criticism inevitably calls my race into question. It questions my performance of blackness merely on the basis of an intimate relationship, on my chosen partner. And for some it also inevitably links my selection of a white partner to a performance of class, as if to suggest that if I were not Dr. Alexander, I would be with “an average black man,” what ever that means (p. 313).

The complications of race, sexual orientation, and professional occupation all come into question, and play an integral role in Alexander's identity. He senses the racism around him, not only from his African-American peers on his sexual orientation, but also for his partner who is white. "For men of color, racist attitudes complicated their developmental process because they often had to maneuver through homophobic tendencies in racial 
communities and racial prejudice in gay communities” (Stevens, 2004, p. 202).

D’Augelli (1994) proposed six stages that help to understand sexual orientation identity development, they are: exiting heterosexual identity, developing a personal gay identity status, developing a gay social identity, becoming a gay offspring, developing a gay intimacy status, and entering a gay community. The theory emphasized that each person's development was uniquely different from the other and environmental factors and intrinsic factors influenced the development (Stevens, 2004). In the case of Alexander, the influences of race and sexual orientation on his identity are hard to distinguish and often times the lines between each are blurred.

Gender is another factor that can sometimes become have a passive-aggressive role in identity development. Torres et al. (2003) points out that some women who side with their identity as a Latina or a female depending on the situation. Like other racial minorities, women are frequently overlooked and unaccounted for in terms on their development. Helm’s (1990) theory of identity development is quite similar to Cross’ (1971) model. Helms model proposes four stages: pre-encounter, encounter, immersionemersion, and internalization. Like other race models, females explore their and discover the roles of being a female in today's society, and depending on the environment she is in, will be able to develop positive affirmations about her identity as a female. Environmental pressures will likely influence which identity (race or gender) comes out. Another example would be a female engineer, because of the lack of diversity in this field (mostly men make up the field), women may feel more inclined to express her identity, or internalize negative aspects of female identity because she feels threatened in the field. Race and cultural ties often play a big role for women, for example traditional gender 
roles of Latina women often force them to choose the family over education (Leyva, 2011). In this scenario women's' identities as professionals come into conflict with their Latina identities. The identity theories mentioned so far all mention environmental factors that influence identity. External influences greatly affect a person’s identity, no matter the race, gender or sexual orientation. The next section describes this phenomenon as place identity.

\section{Place Identity Development}

The research refers to place as a connection between an individual in their relationship with their surroundings, and as described in chapter two it includes a person's history, culture, perceived roles, and experiences associated with that environment. In short, place refers to "those places which can be directly experienced by a person and which are subjectively meaningful to him or her. It is through this concrete relationship that the environment attains its symbolic significance as a substance of social, emotional and action-related contents” (Lalli, 1992, p. 285). The term place identity is used in this research, but other similar terms in existing research describe some of the same phenomenon, these include: attachment to place, sense of place, regional identity and regional consciousness.

When looking at a person from a racial perspective, as mentioned in previous racial theories, we must respect their immediate surroundings and external factors in their neighborhoods, communities, towns, states and even nations. By looking at these we can begin to understand where beliefs about their identity come from. A classic example is the individual who grew up in an "inner-city impoverished neighborhood", who now is in college but somehow feels he still does not belong there. Introduced back by Fordham 
and Ogbu (1986), "acting white” is still a label, and fear held by many individuals coming out of these communities, especially for minority students. Therefore the lines between place (i.e. neighborhood) and group (i.e. ethnic minorities) regularly overlap, linking place to affect a person’s identity (Proshansky, Fabian, \& Kaminoff, 1983).

Kana'iaupuni and Liebler (2005) summarize the impact of a sense of place for Hawaiians and part-Hawaiians:

... where individuals have a have both Hawaiian and other racial heritages, physical and symbolic ties to the land of Hawai'i are to key to Hawaiian racial identification. The deep cultural value that Hawaiians place on physical and spiritual connections to the land, the importance of genealogical family and ancestral ties, and the underpinning effects of colonization all heighten the role of place in Hawaiian racial identification processes in mixed race households (p. 711)

Here place not only includes the physical environments, but also the historical experiences, like colonization and intangible experiences, like the spiritual connections to the land. It is these examples that the sense of place identity and region identity blur the lines. One can take many angles when trying to isolate identity; we can take a racial (or gender) perspective and look at its historical experiences and relations to society, but in doing so we forget to consider the other factors that cannot be measured by the outside, and only understood by the individual; like the connections to the land (or other artifacts) or spiritual connections. Place may also serve as reference points, which we often use to compare ourselves at different times in our lives to keep a sense of continuity with our 
changing identities (Korpela, 1989; Lalli, 1992). As we develop as individuals, we are often reminded of the person we were, and the person we are presently. Using place as a historical device, we try compare and contrast our past with our present to make sense of the path we have paved for our self. If conflict occurs within this stage, we may or may not regress to a previous identity, or carry on with a new one.

For those, who were of a mixed race (i.e. belonging to more than one race) a sense of place was a major influence on their identity. I for one understand this very well, being part Hawaiian, Filipino, and Chinese; I often look towards my Hawaiian heritage for answers. This is a connection that I feel toward my Hawaiian ancestors, and yet I know I am influenced by my racial identification with my Filipino, and Chinese background. I am also influenced by my immediate surroundings in the world of academia. At times I do feel like I belong within the university setting, dressing in my business casual long sleeve collared shirts and slacks, teaching classes and speaking on panels. And at the same time I feel like I do not belong, and I yearn to go back to Hawai'i, “talk pidgin English”, in my Aloha shirt and pants attire, and not adhere to the formal rules of academia. So to put a label and try to define who I am in terms of race, gender, or even place; is something even I cannot fully comprehend.

\section{Imagined Communities}

A sense of belonging or identification is not limited to the immediate physical surroundings, it can transverse over time and space making the boundaries limitless. In this sense communities can be formed with people we never met but yet when we met them, we feel a common bond and a certain level of comfort, as if you already knew the

person. Even those we do not meet, we somehow feel connected and feel a sense of 
community (Kanno \& Norton, 2003). Benedict Anderson coined the term “imagined communities" which he uses to describe peoples identification with a nation. "It is imagined because the members of even the smallest nation will never know most of their fellow-members, meet them, or even hear of them, yet in the minds of each lives the image of their communion” (Anderson, 2006. p. 6).

A common example of imagined communities occurs during the Olympic games. For most, during this time people tend to identify with their home nation (i.e. United States, Germany, China, etc.) a lot more. Now even though we do not know everyone in the imagined community, we still consider each member (i.e. fellow American) a close acquaintance of ours. The same phenomenon happens at smaller levels like home states within America. Those from West Virginia will find a lot in common with another person from West Virginia; just I would when I meet someone from Hawai’i. Take it a step further to micro-levels and find that these imagined communities flourish within towns, cities, and even at the organization or even social clubs level.

The McNair scholars program is nationwide, with 200 programs across the United States, just as Americans will never know or meet one another; the same goes for the McNair scholars. They may never know each other, but will share the same bond to Ronald E. McNair and his accomplishments in his life. His legacy drives the McNair scholars program. Each and every scholar has the drive to go on, and will find similarities and common bonds with McNair scholars they meet in the future. The sense of community amongst the McNair scholars creates this imagined community that they eventually become a part of. 
However it is the imagined communities that each person constructs that drives his or her beliefs about that place. Take for instance; on the east coast I rarely find a person from Hawai'i, but when I do, the person I meet and I both get excited talking about things we remember in Hawai'i, and how much we miss it. However we may find that the Hawai'i we both talk about could be totally different depending on our experience. Hence the imagined Hawai'i (it could be real or not) is the driving force behind our identification. Kanno as cited in Kanno and Norton (2003) found a similar finding with a Japanese teenager who struggled to keep his “Japaneseness” even though he held same values as the Canadian teenagers.

...however his “Japan” was an imagined construct that had little resemblance to the "real” Japan that he was later to experience when he returned to his country...because [he was] away for so long, he had little experiential knowledge of Japan on which to build his allegiance. What he lacked in substantive knowledge, he compensated for with his powerful imagination. When he finally discovered that the "real” Japan was far removed from his idealized Japan, his disappointment ...led him to not want to be Japanese anymore (p. 243).

Confronted by the “actual” reality, caused this individual to drop his imagined community membership. However this story exemplifies the influence of such a phenomenon, the "imagined community created a powerful vision, giving him [individuals] an important sense of direction” (Kanno \& Norton, 2003, p. 243). Imagined communities are able to influence a person's identity based on what that person thinks the community was, is, or what it represents. 
Individuals do not have to belong to a social class, race, gender, region, organization, or any other form of community to be influenced by norms held by that group. Through our own imagination we are able to construct these imagined communities, which are only limited by our thoughts and perceptions of them. For McNair scholars, this is important, because how they view the program, will likely determine the ways in which they are influenced by it.

\section{So what is Identity?}

Identity is a very complex and is influenced by many different factors, whether they are internal or external. The purpose of this study is not trace the history of the scholars to see if they have what Ogbu (1993) calls voluntary and involuntary cast-like minorities, or to categorize what developmental stage the WVU McNair scholar is in, but rather to show that much more than a ethnic identity development model, or AfricanAmerican identity development model, or American Indian identity development model, or Asian-American identity model, or gender identity development model, or sexual orientation identity developmental model, or place development identity is needed when trying to understand an individuals identity. At the core of all identity development theories are the relationships between a conflict and a resolution within each individual and how the environment can influence it. This is an on-going process, and often individuals do not reach that final stage where they find their true identity. For the WVU McNair scholars, the challenge is to adopt the duties and responsibilities of the program,

all the while trying to graduate from their undergraduate schools, and in the process apply and get accepted into the graduate program. This is no easy task, but somehow the 
McNair scholars, although not all, find the motivation, courage, and desire to navigate through the obstacles presented before them.

The identity development of the WVU McNair scholars is crucial in understanding their journey to graduate school. Looking at the goals of the McNair program, it is clear that program's success and effectiveness is measured by their graduation rates getting their Bachelor's degree, and ten years later their doctoral degree. Students from this at-risk population may be vulnerable and confide with the dominant culture values, in other words, do McNair scholars from racial minority backgrounds view academic achievement as a "white” thing? (Fordham \& Ogbu, 1986) or something for the privileged dominant culture? Or are they able to find a balance between their perceived identities? And reach a level of commitment where they are comfortable with who they are now, or becoming. This study will look at individual experiences of each scholar and the effects of the McNair program as students traverse through the various stages in their identity development in the undergraduate and graduate level. 


\section{Chapter IV}

\section{Methods}

The research project used an autobiographical approach explaining a phenomenon that occurred during my time as an undergraduate and graduate student. As noted these student participants as was I, came from marginalized groups in the university, and often times being subjected to the dominant populations, which is why this qualitative approach was used. Qualitative data gives voice to those silenced individuals (Coffey \& Atkinson, 1996), the same students who blindly go through the motions of a college student. The research included: nine individual interviews with WVU McNair Scholars; a document analysis on McNair documents; my own observations of the program for the past three years, and my own experience as a minority and FGS getting into and persisting at the graduate level. All qualitative data sets were triangulated to address the research questions. Using critical pedagogy as the theoretical framework, the study provides a glimpse into the McNair scholar's experiences as they navigated their way through higher education, paying particular attention to the "relationship between the sociopolitical domain and the life of the individual” (Kincheloe, 2007 p. 21).

\section{Phenomenological Analysis}

Individual experiences of each McNair scholar are unique and vary from one person to another. Phenomenology seeks to give meaning to these individuals: “...it aims to identify and describe the subjective experiences of respondents. It is a matter of studying everyday experience from the point of view of the subject” (Schwandt, $2001 \mathrm{p}$. 192). Recognizing that the participants in this study are from a population that does not fit the "norm", the research used a phenomenological approach to describe the 
meaningful experiences and how the McNair scholars reflect on their past, current, and future roles in higher education. By using a phenomenological approach, we try to understand what it like to be WVU McNair scholar, and how the program affects the students view of their own space, voice, and identity.

\section{My Own Experience and Observations}

My own struggles with college and getting into graduate school helped inspire me to carry out this research. Looking back and reflecting on this process I see the same challenges and barriers that I faced in these McNair scholars. Even though I am not a McNair scholar and only the graduate assistant, the McNair scholars have accepted me amongst their community. Coming from non-McNair background I am able to compare and contrast my own experiences with those of the McNair program.

Since the summer of 2009, I have first served as a graduate mentor and eventually a graduate assistant (in 2010) for the McNair scholars program. As a graduate assistant I witnessed first-hand the experiences of the scholars. I sat in on the interviews when they

first applied for the program, as they talked about their hopes and fears of graduate school, and reasons why they want to go on, as well their doubts about they think they cannot accomplish it. I was there with them all through the six-week summer internship as they developed their research proposal and gained the skills to become great researchers. I co-taught the ORIN 493I- McNair Research course that they took during the Fall and Spring term following their participation in the summer research internship. I attended all cultural events and seen the profound effects, and overall joy they got from doing and seeing new things. I helped prepare and watched these scholars make their final research presentation at the national McNair conference, sat with them during 
various conference lunches and dinners, and sometimes drove with their to other academic presentations and conferences. Through my observations I have seen the changes that these students go through from the day they turn in their application to the McNair program, to the final time we say our goodbyes as they receive they certificate of completion when they graduate from WVU. Through conversations with McNair staff, students, and faculty mentors I have gained an appreciation for the rigor that they go through while in program, often being confronted by challenges that push their intellectual and social limits.

My own knowledge and experience with the phenomenon being studied, allows me to also see what is not going on, or what the WVU McNair program is not offering. In other words, there may be some significant service or event that occurred in my journey from undergraduate to graduate school, which help transform my identity. In observations, it is "appropriate to note that when something did not occur when the observer's knowledge and experience with the phenomenon suggests that the absence of some particular activity or factor as noteworthy” (Patton, 2002, pp. 295-296)..

\section{Participants}

The WVU McNair scholars are the most knowledgeable of the program because they experienced it first hand, therefore using this population as participants increased the sampling adequacy (Morse, 1991) which helped lead to saturation and replication in the data analysis stage (Morse, Barrett, Mayan, Olson \& Spiers, 2002). Therefore a purposeful sampling was used to recruit participants for the interview section of the study. A mass email was sent to the 2009, 2010, and 2011 WVU McNair scholar's list serve containing an invitation script for the study (Appendix A). These three years were 
chosen, because these years coincide with my time as the graduate assistant for the McNair program. Prior to sending out the email I obtained permission from the Assistant Director of the WVU McNair program to use the listserv as a recruiting tool. A total of 15 McNair scholars responded to the invitation. To gain a breadth of different experiences within the program, I ensured that each cohort had at least one student that qualified under the underrepresented category, and at least one student under first generation and low-income category. After controlling for these factors, a total of nine WVU McNair scholars participated in the study. Clark and Creswell (2008) describe a legitimation type known as sample integration, where the researcher tries to generalize a sample of participants to a greater population. I realize that not only is the population unique to WVU, and also aware that these McNair scholars are all in graduate school. I am aware of these issues, and therefore restate that the research is being done to explore the experiences of these scholars and I am not trying to attribute the findings to other McNair scholars, but rather provide rationale to help understand the experiences associated with being a McNair scholar.

\section{Participant Background Information}

The following is a general background of each participant. To ensure his or her confidentiality each participant was each given a pseudo name and general background information is provided to help understand the unique backgrounds that each scholar came from. The background information uses a lot of generalizations to protect the identity of the McNair scholar participants.

Jane. Jane is an African-American female who grew up in a rural southeast town. She came to WVU as a transfer student in her sophomore year of study. Already 
involved in a multitude of extra-curricular activities, Jane had her mind set on obtaining at least a Master's degree but never really thought about getting as far as Ph.D. Jane as she puts it "was in the right place at the right time" as she found about the McNair program, moments after hearing her other plans for the future fell through. She graduated from WVU's College of Physical Activity and Sport Sciences, and is currently at another southeastern university pursuing her Master’s degree.

Nathan. Nathan is a Hispanic male, who moved to the United States at a young age. Separated from his mother, who stayed in his home country, he grew up in northeastern inner-city neighborhood. Joining the program, late in his senior year, Nathan spent the least amount of time with the McNair program, as compared to the rest of the cohort. Like most minority students, he was unsure about the process of the obtaining a doctoral degree, and could not find the support amongst his home community. Upon graduation from WVU's College of Arts and Sciences, and he immediately enrolled in Doctoral program at a eastern university where he was awarded a fellowship.

George. George is a Hispanic male non-traditional student. He started out attending a small western community college. Wanting to get away from his hometown, he transferred into WVU without knowing anyone in the town or university. Being deferred the first time he applied, George applied and got was accepted into the program in his senior year. Already involved in a research project with his faculty mentor, George felt like he had the research skills, but felt out of place in academia because of his low GPA. After graduating from the Davis College of Agriculture, Natural Resources and Design, and pursued his Master's at a mid-west university. 
Travis. Travis is an Asian-American male who moved around a lot during his childhood. Living in more than three different states, he often refers to his southeastern rural community where his grandmother lives, as his home. Unlike most of the minority students in the WVU McNair program, Travis already had his mindset on a Ph.D. as a young adolescent in high school. Although he already made up his mind for this goal, the admitted that the McNair program helped him a lot terms of making him a better candidate for graduate school. He graduated from WVU's College of Arts and Sciences, and is now pursuing his doctoral at a Midwestern university, where he continues his doctoral studies as a research assistant.

Katy. Katy is an African-American female, and like Nathan, Katy also moved to United States as a child, and grew up in a community in the northeast. Katy came into the program, unsure of her current major as well as future intentions after college, being caught between the demands of her home culture and personal academic interests; she eventually switched majors, and found something she enjoyed a lot more. Like Jane, she too was actively involved in the WVU community. She graduated from WVU's Eberly College of Arts and Sciences, and will be taking a term off, before pursuing her Masters degree at one of the three colleges she has been accepted to.

Lisa. Lisa is an African-American female, whose roots trace back to the Caribbean islands. She too moved to the United States after finishing up some college back in her home country. As a self-described non-traditional student, she was older than most of the McNair cohort. A Ph.D. was also a goal prior to joining the McNair program, she had clear set goals and had a busy schedule; having a part-time job while 
attending WVU full-time. She graduated from WVU's Eberly College of Arts and Sciences and took a term off to continue working. She is currently living in a northeast urban city, where she will be enrolling in a Master’s program in the Fall 2012 term.

Tracie. Tracie is an African-American non-traditional female student. Not being happy with her past career, and wanting to become a counselor, she came back to college. Already possessing the drive and desire to become a counselor, she was still unsure on what educational credentials she needed to get there. The McNair program provided her with the information and training she needed to get there. After graduating with a degree from the Eberly College of Arts and Sciences, she was accepted with funding, to a large south-east university, where she currently holds a teaching assistant position.

Dianna. Dianna is a white non-traditional female student. Being a single parent and full-time student, Dianna led a busy life inside and outside of school. Wanting to pursue higher education was fueled by her inspiration to be a better role model for her child. Being referred to the program by a past McNair scholar, Dianna joined in her senior year. Hesitant at first to pursue higher education, she eventually found a passion for research and its applications to society. After graduating from the Eberly College of Arts and Sciences, she enrolled in a Master's program at WVU.

Karen. Karen is a white female who grew up in a southern rural town. Not wanting to follow in the footsteps of those around, she came to WVU hoping to leave everything behind her. Adjusting to the college environment was no easy task, but with the support of various organizations on campus found college life exciting. She eventually found herself being referred to the WVU McNair program by a faculty 
member. Shocked that someone seen her in their manner, she decided to apply. After enrolling in McNair she graduated with a double major from the Eberly College of Arts and Sciences, and also enrolling in a master's program in WVU for the Fall term.

\section{The Interview}

A semi-structured interview (Stewart \& Cash, 2006) was used for the interview process. The structure provided ensured that participants do not feel as restricted by the questions as in structured interviews and not feel a lost of words as in open response interviews (Stewart \& Cash, 2006). The questions posed, elicited responses from the individuals about their experiences as a McNair scholar. Previous qualitative research (Baness, 2011;Beal 2007; Derk, 2007; Ford, 2011; Gallagher-Trayhan, 2010; Olive, 2010; Willison \& Gibson, 2011) on McNair scholars used interviews as its primary source of qualitative data. Interview questions within these studies primarily focused on the following themes: academic training (how acquisition of specific skills helped), relationship building (how the relationships formed with staff and faculty helped), common barriers (the effects of academic and social pressures), and personal aspirations (why students persist). Questions used in the interview are based on past research (Baness, 2011;Beal 2007; Derk, 2007; Ford, 2011; Gallagher-Trayhan, 2010; Olive, 2010; Willison \& Gibson, 2011) and specific program components of WVU McNair Scholars program. These questions were specifically designed to explore the notions of space, voice, and identity; and how the program affects it. The interview questions being used in this study (Appendix B) relate back to the overarching research questions. Note that some interview questions are listed under multiple times. 
Four interviews were conducted face-face within the WVU McNair office, and five were conducted over the phone, due to students being out of state or were in the process of moving to another state. The interviews were more of a conversation, a time for the scholars to reflect on their journey as McNair scholars, and remember their experiences in the McNair program. The interviews lasted between 30-85 minutes, and for the majority of the interviews, I only asked a few questions from the interview protocol, as scholars answered by sharing their stories, struggles, experiences, and memories of what it is like to be a McNair scholar.

\section{Document Analysis}

A document analysis was performed on the following: WVU McNair website, WVU McNair brochure, WVU McNair Scholar’s student handbook, and conference handouts/agendas/booklets (University of Maryland). The material from the University of Maryland conference was used because this is the one conference that almost all participants attended before graduating (four of the participants in the study did not present at the University of Maryland Conference). I first scanned though all the documents immersing myself within the data. I found this experience very gratifying as it bought me back to the various memories I had with the WVU McNair program. After the open coding stage, I used axial coding (Patton, 2002), to establish the themes that are used to answer the research questions. To help establish trustworthiness and also check to see if the themes that emerged were bias, a second person trained in qualitative research methods coded the data. Any variations or discrepancies amongst the codes were discussed further until an agreement was made. 


\section{Measuring Transformation}

The process where individuals experience a change in their frame of reference is known as transformative learning (Mezirow, 1997). Through critical reflection, individuals can transform their habits of mind and point of view (1997), and when people see themselves differently, as well as others see them differently, then transformational learning has occurred (Clark, 1993).

Stevens-Long et al. defines transformation through a structural development approach where individuals move between different stages of development (as cited in Stevens-Long, Schapiro, and McClintock, 2012, p.185); and in these shifts we move toward a more inclusive, and complex way of knowing. These shifts occur when student's previous awareness and comprehension of reality is met by new and more reasonable ways of knowing. This approach involves the actions and choices bought on to the student in their learning experience; therefore people such as professors, peers, staff, and mentors all play an integral role (Belenky \& Stanton, 2000; Stevens-Long et al., 2012).

From a critical pedagogy approach, transformative learning uses praxis: the process of which leads an individual to a level of critical consciousness. According to Kincheloe, critical consciousness is created through awareness of the self, conditions in which one lives, how you experience reality and how you behave in a world that you do not quite understand (as cited in McLaren \& Kincheloe, 2007). He further explains:

In this context, questions of the social construction of identity are viewed through the lens of affect and emotion. Empowered by such knowledge, individuals with 
a critical consciousness are able to use their insights to overcome alienation and construct social and individual relations with other social actors. (p. 38)

By gaining a deeper understanding of one’s self through critical consciousness and becoming aware of the environment, space is created within an individual that lends to transforming their reality (Freire, 1976). Using the themes that emerge, the research will describe common factors that lead (or not lead) to transformation within an individual. Qualitative research and its sensitivity to the individual experiences welcome the use of emotion, action and cognition when describing the potential transformation (StevensLong et. al. 2012) that occurs within McNair scholars.

\section{Analysis of Interview Data}

Analyzing the data on a personal level helped me to incorporate my own experiences into the data. The heuristic process is a form of analysis that is highly personal; where the researcher immerses themselves within the data, and in the process become informed on the phenomenon involved (Moustakas, 1990). My role as the researcher and also as the McNair graduate assistant allowed me to have "direct personal encounter with the phenomenon....and present throughout the process” (Moustakas, 1990, p. 14). Interviews were transcribed into qualitative data; after transcriptions, all participants were given pseudo name. I read through the transcriptions, and first highlighted common responses to interview questions, which was my first level of coding. After finding connections and patterns using open coding, I again used axial coding (Patton, 2002) to discover emergent themes to help describe the phenomenon that took place within the participants. The same researcher who checked the document analysis themes, coded the interview transcriptions to account for inter-rater reliability. 
Using triangulation, was key in testing consistency amongst the approaches I used (Patton, 2002). My observations, along with the interview data, document analysis and my own experiences provide a rich description of what it is like to be a McNair scholar, and also the experiences of being a minority in higher education. Raw quantitative data (quantitative data not yet analyzed for typology) is used to share the WVU McNair scholar's experiences, providing them a voice to the outside world, and is also used to support the research question. 


\section{Chapter V}

Compared to the WVU McNair scholars, my experience from undergrad to graduate school was much different, that is terms of the path I took. I never really cared about grades. I never took on an independent research project. I reluctantly took the GRE two months before applying to graduate school. I took out loans for graduate school because I did not anything about assistantships, fellowships, or any other form of financial aid. I took two research stats courses, which I barely passed, and I struggled to find letters of recommendations during my senior year. If anything my graduate school application was a meager attempt that I hastily put together during my last semester as an undergrad. When I finally made it to graduate school, I quickly found out, that I have never been challenged like this before. As I took on the challenges and adapt myself to become a part of "them", a transformation was taking place, but I needed to know why this was happening, and why do I feel like this goal of obtaining a higher education, is somehow making me a person that my friends do not recognize, my family does not recognize, and more importantly I did not recognize. All of this was taking place during my time as a doctoral student, which took me by surprise that I was accepted. After all looking at my background I did not have the scholarly grades, GRE scores, or research experience. Why would anybody want me?

\section{Results}

The following sections will be providing the results of the study addressing each research question posed earlier. To understand what it is like to be a WVU McNair scholar, the results follow a chronological form. Starting with the initial impressions of the program from the interview, and ending when the student felt they had undergone a 
transformation, if they perceived one. I will also incorporate myself into the data, and not using the italicized fonts to talk about my experience. Excerpts used in this part of the study, are transcriptions of the scholars interviews. To keep their stories and voices as authentic as possible I have decided not to edit, their slangs, or uses of excess words (i.e. like, ya know).

Arranged in the form of a narrative display, this chapter will address the following research questions: How does the WVU McNair scholars program affect the student participant's identity? And how do the services provided by the WVU McNair scholars program affect the student's sense of voice and space? These two research questions often overlap and influence one another, therefore rather than to try to separate the results based on the questions, I present the results in a manner that reflects their journey inside and outside of the program. To support these questions, the following themes emerged from the document analysis and interviews with the scholars, there are: challenging structure, support, uncertainty, barriers, inclusion, and validation.

\section{How the McNair Program Affects Student Participants Identity}

The tone in the WVU McNair program is set early on with the students. Starting with the interview that students partake in prior to joining the McNair program, they are well aware of what lies ahead. During the interview process, I got to know the scholars, their personal stories of where they grew up, the challenges they faced to get here, the career aspirations of what they wanted to become. However one thing was quite clear. These students had a vague understanding of the graduate school process and none really knew exactly what they needed to do to get there. Those few that were familiar with the process knew that they needed a lot of help and guidance to prepare for the next step. 
When scholars were notified of their acceptance to the program, they describe the initial feelings of joy, hope, and excitement of being accepted into a prestigious program. Just as the WVU McNair program is taking a chance with students by accepting them into the program, the students also take the same risks, devoting their time and efforts to the program, hoping that it will help them in their future endeavors. Together the scholars and WVU McNair program strive toward the end goal of a Ph.D.

Having been to a few orientations and knowing how students eventually turn out after the program, I always find the very first day of McNair orientation the most challenging. I could feel the fears of the students on the air, as I try to make small talk with the students; their answers are very limited, as if they are afraid to tell me their true feelings at that time. If I could sum up the first day of orientation for the scholars, from my observations the only emotions present are: fear, doubt, and uncertainties. I find this to be amusing, because of past experiences with the McNair scholars. They all start out doubting their skills and by the end of the program almost all of their feelings of not being "good" enough disappear. Maybe because I see myself at younger age when I look at them, I think about my struggles, and how I dealt with them. The first day is not only challenging for the students, but also for the staff. It is this first day that we the WVU McNair scholars program need to convince the students that all the hard work and dedication required in this program will eventually payoff in the future. Maybe this is why Derk (2007) was filled with hope for the scholars on that first day. Almost as if we are connected by the program, or maybe we share similar educational beliefs, or maybe we believe in what the program does, either way I too shared the same feelings with every new cohort at their respected orientations. 
The McNair Policies and Guidelines Manual is presented to the WVU McNair scholars at their orientation which takes place in the month of April; approximately one month before the start of the summer research experience. If the scholars were not already aware (from the interview process), the WVU McNair manual, given to all students on the first day of orientation, reminds the scholars of the rigorous work that waits in the summer. The following excerpts demonstrate the theme of a challenging structure of the program: "WVU McNair Scholars are expected to: maintain a cumulative GPA of 3.0 or higher...develop and adhere to a timeline... apply to at least three graduate programs... and develop a portfolio of credentials and research” (WVU McNair Policies and Guidelines Manual, 2008, pp. 3-4). The expectations of the WVU McNair scholars are very high, judging from their facial expressions on that first day, these scholars feel it too. The demands of the program are alleviated with the many types of support offered by the program. The theme support is not only voiced by the McNair staff during orientation, but also clearly stated within the WVU McNair Policies and Guidelines Manual (2008), which exemplifies:

WVU McNair scholars are expected to: Remain in the program until earning an undergraduate degree...consult with WVU McNair Scholars Program personnel regarding problems that might impede meeting any of these obligations...Maintain frequent and regular contact with the McNair scholars program staff... Respond to follow-up efforts on academic and career progress after matriculation from WVU (pp. 3-4).

Yes, the WVU McNair program does ask a lot from their students, however at the same time, the WVU McNair program provides the support that these students will need to 
accomplish these tasks. The program makes it clear, that the services afforded to them are there for their benefit and highly encouraged to be used during their entire time with the program. It is also clear that the program wants to keep in contact with them once they graduate from WVU. Edwards (1993) stressed the need for a challenging structure that is also supportive for the students to help minority and FGS in college. From the flyers, brochures, initial interview, and policy booklet it seems that the McNair program challenges these students and also provides support for them. From my observations and document analysis it may seem that the McNair program addresses these concerns for minority and FGS, however how did the students perceive what was being offered?

Once the Spring term has finally ended, students take two weeks off before embarking on their intense summer research experience. The first class is when the fears, doubts, and uncertainty of each scholar come to surface. The daunting task of completing a research proposal in the next six-weeks always hit home with the scholars on the very first day. The theme of uncertainty describes these students' experiences, Jane reflects on her first day:

In the beginning, I think myself and everyone else was kind of scared that everyone around them was smarter than them and maybe [they] had more experience... Not having any experience with research. I thought I might fall on my face, because you guys were really intimidating with the research expectations (Personal interview, Jane, 2012).

Katy felt the same pressure from the McNair program: "I was just thinking, wow this is a lot of work, this is an intensive program, and like they really expect a lot from us...it felt 
a little overwhelming." (Personal interview, Katy, 2012). At first Tracie felt like she was capable of accomplishing the work over the next six-weeks but eventually found that the pressure of the whole program finally cracked her:

I think it was starting to sink in, and that I never really done research before, and I have to do what?... like what type of project...like how many pages?...literature reviews and all that other stuff...[it finally hit me and]maybe like a realization, [how I]was really going to be affected [by the program]” (Personal interview, Tracie, 2012).

Challenging these students and forcing them to do things they never did before is what the program does. This is not done in a cynical manner, as a process of weeding out weaker students, hoping that they will drop out because of the pressure. From my observations and what I understood is that the program trusts that these students are able to complete this tasks in the limited time offered. The trusts and confidence that the WVU McNair program has for their students helps to build the foundation of the sense of community that these students will confide in throughout their time with the program. The uncertainty and pressure that these students felt in the beginning are normal (Derk, 2007), where the scholars who are filled with doubts and uncertainties seek out support from their surroundings. Dianna speaks for all the scholars as she sums up what the beginning of the program was like: "It turned out a lot of us were on the same page " (Personal interview, Dianna, 2012). All nine WVU McNair scholars shared the same feelings of pressure, although each approached it and handled it differently; it was quite obvious that the WVU McNair program had a challenging structure. 
It is also through their uncertainty that we begin to understand the WVU McNair scholars as individuals who found them selves sometimes feeling alone in the unknown world of academia. The theme of support, is useful to explain how students were able to survive the demands of completing the research proposal during the summer, conducting their McNair research project while being a full time student in the following Fall and Spring term, applying to graduate schools, taking the GRE, polishing up personal statements, putting together a CV, and presenting at a national conference. One can clearly see, as did I, the stress of meeting these demands. Yet somehow these students thrived in this environment. Travis mentions the support that helped him the most while with the program:

It was really useful to have someone who was ... encouraging and to help me along the way, and let me know that it's really not as scary as it may seem to be, so ... [that's] probably the best resource I had... It gave me the skills, and...It gave me the like mentorship that I needed to move forward in the path that I wanted to move forward in. (Personal interview, Travis, 2012).

Staff of the McNair program mean so much more than mentors for these students. Dianna describes her relationship with one of them: “[one person] especially was I mean she is a friend and even like a parent figure at times too when things are falling apart, I can just go to [that person] for help”. Having someone close was very powerful for Dianna. Being a single mother, she felt that, that particular staff member understood not only the struggles of doing scholarly work, but also meeting the demands and responsibilities as a parent. This was not always the case for Dianna; she also felt that 
others did not understand her background and her responsibilities outside of the classroom:

[Some are] just not real personable...not everyone's life can be engulfed in McNair...I had a kid and there were times when I had to go home... and it was if [they] scolded me as if I was a child, “well why do you have to leave?”. (Personal interview, Dianna, 2012).

For Dianna, the McNair program goals and her personal responsibilities as a mother clashed. She had a strong attachment to her identity as a mother first, and scholar second. She made sure not to compensate her identity as a mother for anything. From Dianna's example we see that the lives of the McNair scholars are much more complex and their lives outside of the program are intertwined with their McNair experiences.

\section{Understanding Where They Came From}

Edwards (1998) express the need to understand where these minority students come from, we need to recognize their issues outside of the university, and that we often forget that the ones that made it to college, are the "lucky ones." The WVU McNair scholars each have their own unique story that they bring with them into the program. More often than not, I seen that the scholars rarely find the support they need outside of the McNair walls. The research (Striplin, 1999; National Academy of Science, 1997) shows that families of minority and FGS did not experience college first hand, therefore do not understand what it like to go college, and even have a harder time understanding why someone would want to further their education. The theme barriers arise when these scholars start to talk about their lives outside of the McNair program. Jane, who admires 
her family, and frequently visits them when she has time, finds that the support from her family is of mixed signals. Her immediate family is proud of all of her academic achievements so far, and ecstatic that she is going to graduate school. Yet there are still those who do not understand:

I know there's some people in my family that are just like, Oh my god, you're just gonna be a professional student. Why are you still going to school? Nobody wants to do that. You're gonna be in so much debt (Personal interview, Jane, 2012).

Lisa received the same feedback form her family, who did not understand:

Like my older brothers, my mom. They'd be like, What? You're not tired of going to school? You're wasting all of this money going to school. Why don't you just work like a regular person and save money and get your life together. And even some of my friends... And I guess they wanted to benefit from me working because you know families from the Caribbean request that of you... Sometimes I wish I had more support. I think I would have gotten a lot further faster if I had that type of support from my family members (Personal interview, Lisa, 2012).

For George, those back home, did not really understand why he was going to graduate school:

I mean I think that like my friends back home in [home state] They think I ... I mean they've never told me this, but I'm sure they think I'm like lazy and that I don't wanna work and that's why I'm deferring loans, not getting a job, and just going to school more you know. But I don’t think they understand the way the 
school system works. I don’t know. Cause I know they're talking smack all the time about it (Personal interview, George, 2012).

These feelings of not being understood and constantly being judged by others close to them are common amongst the McNair scholars. For Nathan, coming from an impoverished community, he was one who went against the norm. Asked about his peers back home, he responded:

I think I'm the only person in my whole neighborhood, my whole housing apartments that I lived in, I think I'm the only person to ever get a Bachelor's degree, nevertheless, being accepted into a Ph.D. program. Most of my friends, due to the conditions that they had with no parents and living in an impoverished community.... None of them really had the opportunity to go to college and to really experience what I go to experience (Personal interview, Nathan, 2012).

Nathan talks about his family briefly, who is still out of the country, and how they felt about going to graduate school:

They were skeptical about where I was going and [if I] was really that smart...Ya know I'm not too close with any of them for them to know my GPA. So they didn’t know how smart I was or that I would be about to get into a Ph.D. program, so It was strange for them to know about me getting in a Ph.D. program for free I mean. Full tuition and ya know the conditions that I got the stipend and all the things I was able to achieve (Personal interview, Nathan, 2012).

Even though he is not close with his family, it was a surprise that he decided to go on to a Ph.D. Like the other scholars it is not so much the lack of support he received, but the 
absence of their families believing in them, which contributes to the lack of support outside of the classroom. Karen's story expands on the absence of support and stereotypes of people back in her home town:

I don’t think people expected me to go college...back in [my home town] everyone thought that I was gonna be like everyone else, like all the women in [my home town], they get pregnant, have lots of babies and never leave the place,

I don

't know, to me it was

guess I was different...so when I told everyone that I wanted to go to college, it was shocking, it was weird...so when I first left for college, I didn’t think my family supported me, I mean financially they couldn

't, but what I mean i don't think they understood college, so because of that they couldn't support, they just didn’t know how (Personal interview, Karen, 2012).

The familial responsibilities of being a minority as well as a female is common struggle (Torres et al. 2003; Leyva, 2011). However these family ties, are not always a burden on the McNair scholars, at times they provide the foundation for the driving force to succeed in academia. As was the case for Dianna, who found inspiration to go on to graduate school:

The aspirations for me going to get a my Ph.D...I think I'm a little but different then everyone else because mainly my driving force is my daughter...I wanted to make sure that I could provide for her....and I expect her to do just as good, if not better than me.... and I never wanted to have to deal with the question of "you 
didn’t finish, you didn’t go to college, why do I have to bother?”...[I needed to] lead by example I guess (Personal interview, Dianna, 2012).

Dianna's role as a mother first, and student second helped her to find what was important in her life not only in the present, but also how her current decision will eventually affect her in the future. Travis found a different inspiration from his parents. Doing everything in spite of them, Travis found his inspiration by resisting. He mentions how his parents play a role in his desire to go on:

From my parents, but not in the way that you might think. It’s not like... I am who I am in spite of my parents [and] not because of them ... A big driving force in my life is to be anything but like them, because my parents are not well-off. They have chosen a life of pretty much laziness and dependence on other people and the government, and that's not the kind of people ... the kind of person I want to be... I put myself through school. I didn’t have any help from family. I had to have scholarships and low income money and things like that. And that is what McNair targets, and I am who I am in spite of my family, not because of them. That's where my drive comes from (Personal interview, Travis, 2012).

Realizing what he wanted from early on, Travis made the decision to use the lack of support as his motivation. Travis unlike the other scholars already made the decision as he did with his friends from back home, to move forward in life, and pursue his future as a doctoral student. Lisa, whose mother and father did not see the value of going on, found her inspiration from her grandmother who pushed her to go on. Lisa also felt that 
at a young age she did possess the academic talents but did not feel like she was getting the recognition she deserved:

I just feel like I want to get this done for myself...Growing up I felt ... . inadequate?...I just felt inadequate because I felt like I had so much potential because I used to place [ a great emphasis on education] . . .Back in the Caribbean, back on my island, there's this thing called first in class, the highest average [or] whatever, so I used to get the highest average and what-not in class, and it wasn't acknowledged by family or anybody else, like highly, like I thought it should be at the time. I just felt like it was a waste, even up until high school. So I'm like, you know what, I've got something to give, and I wanted to you know go further (Personal interview, Lisa, 2012).

The experiences of the WVU McNair scholars outside of the classroom showcase what external factors that many had to deal with along their journey to graduate school. As they began to shift away from friends and families outside of the McNair cohort, they began to grow closer together as a group. The stories begin to paint a picture of the what scholars' lives were like prior to joining the McNair program. Most did not find the support they needed, and sometimes were deterred when trying to pursue anything educational. The lack of support and knowledge related to gradate school created misconceptions of the world of academia, especially graduate school.

\section{Pre-conceived Notions of Higher Education}

Kincheloe (2007) points that cultural politics between individuals and society influence the scholars beliefs about they are and where they belong. What they learned 
outside of the university effected their beliefs about who belongs in education, and who does not. This not only contributed to false knowledge, but also a sense of doubt within the scholars. Just as I doubted my ability to pursue graduate school, so do the scholars. WVU McNair scholars already come in with these preconceived notions about higher education opportunities, and who has access to those opportunities. The themes of uncertainties and barriers guide the student's construction of knowledge and how they see themselves in higher education. For those like Tracie, it was a lack of exposure and knowledge, and something not common for her to do:

One being a minority it's not something that people talk about and it’s definitely [not]within my circle...It's not something that [is] encouraged, like the biggest thing for people around where I grew up was like [to]get a job...You need to make money and support your family if you have one. So nobody talked to me about getting a Ph.D. I mean like education in general. Go far enough so that you can get a decent job and make a decent living (Personal interview, Tracie, 2012).

Jane talks about why she doubted herself in the beginning:

Because once I looked into what McNair was and what they stood for, I thought, Wow they must recruit really smart people. I don’t know. I guess I just never saw myself as being that kid Like I was really good at school, but I was not naturally good at school, I guess (Personal interview, Jane, 2012).

Jane graduated with honors from WVU, and yet as a junior she did not feel like she belonged to that group of "smart people.” From her perceptions, we find that her definition of "smart people” was something that was socially constructed with her 
educational experience. The question is why did she not consider herself "smart"? McLaren (1997) posed the following questions about the social functions of knowledge: “Who gets excluded as a result?, who is marginalized?” (p. 197). In Jane’s case, she has been not only excluded from her own definition of "smart people" but at the same time marginalized because she still does not see or realize why she cannot be a part of that group. Nathan describes his experience with his early education that convinced him of what college would be like:

I guess the beginning was a little hard on me. I didn't care about school or high school. Or I mean my teachers ya know didn't care about me, and I just thought that the educational system was racist, the way teachers treated us in school, so I never cared about school (Personal interview, Nathan, 2012).

The university setting was also something that was questioned, where minority and FGS are left out of the academic setting (Smedley et. al. 1993, Rendon 1994). Some scholars felt that the university did not single them out, or cater to a certain race. While others still felt the university could offer a little more. Tracie shares her experiences with diversity around the campus:

I don't think that it's just good enough to just see black people who are...black professors, and...black faculty, like I don't think that that's good enough. There also has to be that sense that they can relate to us, and we can relate to them because I think...we (minority students) like to be in a place where [we feel] comfortable and understand one another. I can remember going back and forth to the Mountainlair, and you see those two tables, like in the Mountainlair, and all 
the black people sit at those tables. There's a sense of like belonging. I'll be honest, like I went to Columbia over the weekend, and the girl I was with, she was like, “okay now I'm going to take you to the not so good part of Columbia”...like the projects, and even though [I] know crime happens [here], there was like a sense of like, yeah...these are like my people. Like in that same area, there's churches, chicken, and like there's a hair store. There's something that's tailored...for people like us. So I think there has to be that level of understanding somewhere that you know that they're able to relate to us in a way that we get one another...I didn’t meet a lot of black professors that I was like, Yeah, they get it, and [I] got it, and we connected. (Personal interview, Tracie, 2012).

From a critical pedagogy standpoint we see that these students can sometimes feel left out and isolated. Some of the McNair scholars found more things in common with the environment outside of the university. Coming from an impoverished neighborhood, she identified with those in the "not so good part" of town. Everything that scholars identified with was left out of the university setting. All WVU McNair scholars seek out the program because they have a desire to go on to graduate school. With these experiences within the university and experiences outside the university, we start to understand why most underrepresented populations decide not to go on. For the WVU McNair scholars they found a common place, a safe space, a community of learners, and more importantly a place where they all felt understood. 


\section{Within the Walls of the WVU McNair program}

Not having the support from home, and feeling alienated from within the university, the WVU McNair scholars find a space within the McNair program to share their thoughts, feelings, concerns, hopes, and dreams. As stated earlier, the goal of all constructed educational spaces is to create a community (Callejo-Perez et. al. 2004). The theme inclusion shows what the McNair environment, which included the McNair summer class, and the ORIN 147 McNair research class provided the scholars with an intimate space, where everyone involved could relate. For George, the McNair class and a cohort became something much more than a group of peers and colleagues able to talk to each about research, the struggles of being a McNair scholar, and life outside of school. Within the McNair program George found a family:

I think one thing that McNair does, and it was a great example at that place, it just like gives you a group to belong to you know where people with similar backgrounds are trying to get [a] higher education, other than a bachelor's degree... and awe man, like I felt I was a part of a very important group of people, I feel we were like a family (Personal interview, George).

Jane found the space to beneficial especially when talking about the struggles of being a McNair scholar and dealing with all of her responsibilities:

It was really the only time like every Monday I guess it’s kinda what we used class time for and that was our venting session where we could vent about the pressures of going through the applications while still trying to finish up our own research. No other students that I knew of were going through that process. I 
really did enjoy that because like you can't go outside the classroom and talk about what we’re doing. Nobody understands (Personal interview, Jane, 2012).

The McNair provided a safe space for all of these scholars, but more importantly it was a place where they found a voice. The similarities of their past experiences and future aspirations helped to renew their sense of identity as scholars. Most of the scholars did not have the total support of those outside of McNair, which at times made those scholars feel alone. Nathan reflects on how the McNair class provided him with this space:

McNair breeds that kind of climate, that space for you to talk about your future goals and ya know making them real, and I never would have had a conversation with anyone else except my McNair cohort regarding graduate school. So, yes, that class was itself was unique in that sense that was the only time that I really had any conversations with anyone about graduate school and our future goals...that was probably the best part, I think, about the entire program itself. I think [that] certainly my environment at school wouldn't be the environment of those who talked about graduate school or further goals. And to finally meet certain types of kids who really wanted to do this and really wanted to pursue further goals. To me that was amazing. And, you know, the first time talking to these people about our goals and all of us talking about, “I applied here,” "I applied there,” and then a few weeks later actually finding out we all really did it. It was amazing to know that (Personal interview, Nathan, 2012).

Even Dianna, a non-traditional student, who at times did not feel a part of the university, found a space, where her voice as well as others are welcomed: 
It felt great that a whole lot of other people working toward the same thing...I think that even if they are not in the same field, they understand that we have similar goals...they're more willing to listen...and its nice to have someone who can understand...a lot of people outside of program don’t understand what it is like...(Personal interview, Dianna, 2012).

Like Dianna, Lisa felt that sharing her goals and stories to those who want to listen was a great experience:

It was exhilarating because I remember this young lady who sat next to me...spoke about her goals about being a [therapist]. She just made me so excited about the future and life because she seemed so excited about her goals. Despite her uncertainty about ... her career choices ... she just made me so excited about my future goals and putting it all together...It definitely made it a lot more comfortable to express yourself, because everybody's pretty much on the same level as you were and there was comfort in hearing others‘ stories ... It was interesting to share mine also (Personal interview, Lisa, 2012).

Katy found relief in knowing that she was no longer alone in pursuing her dreams:

It makes me feel good because it gave me the comfort and the realization that there's other people that has the same goals as me...it makes me feel good knowing that there are others out there wanting to do these things (Personal interview, Katy, 2012).

When space is filled with life it becomes place (Callejo-Perez et al., 2004). The classroom environment for the McNair scholars became a place where they could all 
come together; it became a safe haven to talk not only about research, but also life in general. Scholars who were unsure of their future and career found a place where everyone could relate. Knowing that others felt the same you did about school, and also to come from these communities where school is not a top priority, really was energizing for the scholars. Finding their voice amongst other scholars provides a space for the scholars' identities not only as researchers but also as individuals. Tracie expresses how the classroom experience gives you the best of both worlds:

I think the class provided support. I think emotional support and then ... I think sometimes ... like I don't know if I'm just a mushy person. But like there was days I was just happy to go to class and see everybody’s face. . . Just having that support system, even if it wasn't particularly focused on research, that helped a lot for me, and I think when it comes to academia, I think there are things that I talk to people about in McNair that like you know we get it, we understand it, and there's a feeling of comfort there, and then but at the same time we can talk about what's the best place to get frozen yogurt, too, but I just kinda feel like there's sometimes there's a level of conversation that I can have with somebody in McNair that my other friends wouldn’t get (Tracie, Personal interview, 2012).

Even for Travis, who was ambitious at a young age and was already focused on getting to graduate school, found exactly what he was hoping for within the McNair program, he expresses his excitement about being amongst the other WVU McNair scholars:

I thought it was about time, pretty much, like in undergrad...You're with a group with everyone. Right? In this country, we encourage people to go to school who 
like to go to college who don't necessarily deserve to be there, and it's not really in line with what they want to do. And in the long run it’s just kind of what they are expected to do. So when you finally get down and you're sitting in a classroom with a group of people who are specifically targeted, like they're a group of people with ambition, that are competent, and are choosing to further their lives in a meaningful way. Then it's refreshing and encouraging for you because that's the is the kind of atmosphere you need to really I guess blossom into the young adult that you need to be for a doctoral program (Personal interview, Travis, 2012).

Even for scholars like Travis, who was motivated to get a Ph.D. prior to joining the McNair program, found the space within McNair to be useful.

Within the walls of the WVU McNair program, we find that these scholars thrive in a unique environment that is catered for their growth. As if shielded from the outside world, the WVU McNair scholars find a space where they can communicate in a deep and authentic manner, creating a community (Bickford \& Wright, 2006) within the walls of program. This sense of community becomes a their support system in which many of the scholars rely upon as they move closer towards their personal goals and aspirations.

\section{Expanding the Walls of McNair}

This sense of community established, is not limited to WVU program, the community is really a nation of scholars. United by the Dr. Ronald E. McNair's ambition to obtain a doctorate, these scholars have more in common than they really know. One of the common conferences is the University of Maryland McNair Conference. 
Before they can become a part of this community though, the scholars must look past the physical appearances of the McNair program at the national level. I consider myself to be very accepting of other cultures, and especially sensitive to ethnic backgrounds and cultures. So for me it was an eye-opening experience at my very first McNair national conference. It was held at a large Eastern university, and to my surprise, African-Americans made up the majority of all groups there. Even the speakers, and professional staff were mostly African-American. Coming from WVU, and looking at the diversity we bought to the conference, I was curious to see how they would react to being in such an environment. From Tracie's depiction of the McNair conference, she finds the same scenario:

...you kind of draw the conclusion that like Ronald McNair was black, and its like first generation college students, and he was black, so they're probably black, and a lot of our parents didn't go to college so I just kinda figured there'd be a lot of black people, which was true (Personal interview, Tracie, 2012).

Karen, felt the same way at her first conference:

It was weird at first that there was a lot of Black people, I mean coming from where I ' $\mathrm{m}$ from, there isn' t much shocking, but I mean it didn 't bother me that the [at the conference] were Black...what I got though was that we were all the same group, all minority (Personal interview, Karen, 2012).

Other scholars talk about seeing the same minority represented more than others. Some scholars say there were more African-Americans, while others found more Hispanics. 
Either way, the over-representation of one minority did not pose as a barrier to any of the scholars, all of the scholars' feelings, can be summed up by what George had to say on the topic:

Well, I might be wrong, but I saw more African-American than any other group...but that's just me, and I don’t know, I identify [with] any minority I feel like we're in the same boat, so it's not really of whether you're black or you're brown or whatever you are, it’s more of like we go through the same things so you know. It doesn't make me feel any less or any more (Personal interview, George, 2012).

What really amazed me about these scholars was their level of maturity and understanding of the bigger picture. These students, all proud to be McNair scholars found that even though it may seem overpopulated by African-Americans (or Hispanics), each scholar found that it was not the skin color that mattered, but rather belonging to a minority group who experienced the same challenges from the dominant culture.

At the national conference, WVU McNair scholars find the same sense of community amongst other scholars. The WVU McNair scholars began to see that they were not alone on this journey and that others share the same aspirations that understand the struggles in trying to achieve these goals. By discovering that they are not alone, the WVU McNair scholars found a voice not only amongst those who understood what the journey to higher education: Katy found at the conference, a bigger support system, one that went beyond the WVU: 
Its one thing to believe in yourself and another thing to have other people to believe in you also... Because if you don't have this you are basically alone and its kind of hard to do things when you are all by yourself and alone, you have no support system (Personal interview, Katy, 2012).

Lisa echoed the same concerns, and spoke about what it was like to be at the national conference: "It made me feel like I was part of something big. Yeah, I felt like it was like you know nationwide, like not just a commitment but a brotherhood or sisterhood thing going on that was outside of WVU” (Personal interview, Lisa, 2012).

When scholars were able to connect their histories with each other, it helped to validate their own history and experience, and once they were acknowledged, with this voice, they could begin to take control of their lives. (Belenky, Clinchy, Goldberger \& Traule, 1986; Freire, 1993; Gilligan, 1982). Nathan shares his excitement on finding others who come from the same upbringing:

I've never seen that many young people really [who were] so motivated and driven all of them with ya know goals of doing something.. I met a lot of Latinos or young males, who were really interesting individuals in what they were researching, and I just thought it was great... that was great because meeting people who were who were going to graduate school and applying to graduate school. These kids were really good students. . . They were telling me all about their McNair program there. They're like, "Yeah, we had a kid last year who went to this school.” And, “Well I’m applying to Notre Dame for Latin American Studies.” And something big like really elite programs, and I was like, "Damn, 
that's really good that you guys are able to have that opportunity.” And ya know they were telling me about some of their own encounters in their neighborhoods, predominately Latino neighborhoods, impoverished neighborhoods, and they were also really fortunate to be able to go to school, and so that was cool to know that there's other people like me doing the same kind of research and pursuing the same kind of goals (Personal interview, Nathan, 2012).

For Nathan, it was really important to know that others were going through the same things as he did. Even though he never met them before, he connected with the other scholars based on their past histories and future intentions. Enthusiastically he talked about their similarities and how they were doing the same things as he was for similar reasons, only at a different place:

They were from a Chicano community of Mexican-Americans, and, from what we were talking about, they definitely do. And even in school the said they were struggling with both [cultures]. Most of them went to white schools or historically white schools, and...joined Latino fraternities, and were trying to use the cohesion in these fraternities to find identities for themselves on campus, so I thought that was really cool and interesting (Personal interview, Nathan, 2012).

Even though Nathan just met these scholars, he felt a connection that this group of people understood him, and even though they never met, it is as if they knew each other their whole lives. George shares the same feelings as Nathan on this subject:

...everybody was really friendly, and everybody that I met was kinda just the same as me you know. Like especially the people I met from New York. You 
could tell they were into their school, and they did their work and stuff. You could see they had the hood in them. So, I just feel I could relate to them it doesn't matter if I knew 'Exhadr. notctually I met this girl she was from the Bronx, and we were talking for a while. We were talking about her project, and then we just started talking about life you know. It was pretty cool to get to know somebody and see that we have similar stories (Personal interview, George, 2012).

George began to draw on the importance of what this group of people meant to him: I’ve never seen a Chicano professor in the sciences, in the sciences. You usually see Chicanos in either Chicano studies or in the social sciences. You never see them in our sciences you know. For me, it was cool seeing people who would eventually fill those roles for the ... for other Latinos like me you know. So yeah, I guess because there are no role models, we kinda have to identify with each other and try to find somebody that has similar stories to you (Personal interview, George, 2012).

At the national McNair conference, George found space that instilled hope for his future. Not having the support from back home, he found a group of peers who also served as role models. In George's case, he can now reclaim a renewed sense of pride and hope in his Latino identity (as well as his identity as a scholar). Not having a Chicano role model in the sciences, George would question himself if it really were possible. Once you found him self immersed amongst a community of people who came from the same background, same ethnicity, and people who understood him, he began to reclaim his 
sense of identity. Finding a voice within the academic community, he empowers not only him self, but all those included in that select few who shared the same experiences.

The whole conference atmosphere was engaging for the students. All scholars are greeted by faculty and staff in attendance. Presidents. Vice-presidents, provosts and professors of the host university greet all scholars offering words of wisdom and advice. The key note speakers always leaves this students inspired, feeling that they are a part of something bigger then the McNair program, and that they have responsibilities not only on them selves but also to future and past scholars as well. The conferences provide that same space that WVU McNair program provided the students back in Morgantown, WV. Scholars come away from the conference with a new sense of pride and accomplishments, bringing back with them a newly found hope and confidence that the WVU McNair staff had for them from the beginning. The national McNair conferences were always catered to minority students, and is one of the reasons that this students always felt welcomed. Unlike other professional conferences, the sense of community and comradely is not always present. Tracie briefly talks about this:

I kinda felt that way when I went to [a non-McNair] conference and there were other people presenting posters, presentations, etc. [but there] was a lack of connection with other people... I didn’t feel a bonding or connection between them (Personal interview, Tracie, 2012).

However this is not always the case, for Travis, although he enjoyed the McNair conferences, he felt that they were missing the bigger picture with diversity. Wanting to 
branch out more, he felt although the McNair conference was great, it is almost counterproductive to have these students isolated at their own conference.

When I'm around a group of minorities, I consider it to be a group of people who aren't focusing on race as much in terms of feeling singled out. I mean this is a big group of people who have probably been singled out in their own personal lives, so I don't know. I doubt that they were or worried while they were there about being singled out based on their race. It's not the racial minority I think that matters. It's the disadvantaged I guess. And that does tie in with the race thing also, but that's not all that McNair recruits? It's also like first generation and also ... and nontraditional students, so there's older students that can be white for instance. I think if you focus on minority you're like missing the point of like minority status shouldn’t matter. Like people shouldn’t focus on race. Like, I don't know. If you make a conference based on race then you're missing the point (Personal interview, Travis, 2012).

Travis felt that these conferences that was filled with bright young minds who happen to be from underrepresented populations should have the opportunity to present to those outside of the minority groups. He felt that everyone already understood the struggles, and that this conference space, although it was safe, he felt that the scholars were strong enough, confortable enough to present to others.

These conferences represented much more than an community, all the scholars were able to relate to each other even though they never met. As if connected by Dr. Ronald E. McNair, these scholars find a voice amongst the crowds. Hailing from similar 
backgrounds, whether it is the streets of New York, the southern town in Georgia, or suburbs in California, all these scholars come together for a greater cause, which is to support each other on this journey. Benedict Anderson's imagined communities (2006) helps to describe the scholars feelings on connectedness. The national conference helped all McNair scholars to see that they are in fact very similar, and even though they will never meet every single McNair scholar, they identify with the others no matter where they hail from. Through this connection we see that the support system for these McNair scholars are not bound to WVU, or a conference setting, the support system exists throughout the nation. All McNair scholars find it comforting that no matter where they go, they will always have this connection to other McNair scholars.

\section{What Lies Under the Surface?}

As McNair scholars gain new skills for graduate studies, their appearance, dialect, and overall ways of thinking shift as well. Although these new skills are desired in the academic field, it can sometimes have the opposite effect at home. The theme barriers underline the stresses that arise when scholars begin to feel a conflict within their identity. Nathan's desire to fit in both academic and home cultures forces him to adopt two different speaking styles:

How am I supposed to talk at home? We speak vernacular English here or Ebonics. We speak ya know English that is broken down, but at school I'm supposed to speak in a standard format, academic English, so, at times, I come to these collisions all the time, because sometimes I wanna just speak how I speak at home. But yet if I try to speak how I speak at home at school, then it is often seen as I'm a degenerate or as I'm a city hoodlum and vice versa. If I try to speak 
academically at home, I'm looked at as a sell-out. I'm looked as I'm trying to sound smart or I'm trying to sound white or these accusations that are really just not clear or can't define me in any way...Until we understand until I'm understood that as a human being as a multi-dimensional human being that I'm culturally versatile, that I could do both, that I could still be part of my street culture and part of my community and a part what I of the way I was raised but still could ya know be an academic and be a scholar and all that (Personal interview, Nathan, 2012).

The clash between how we speak at home and at school tend to define us in each environment (Kincheloe 2007) and is detrimental to our identity development, it forces us to choose one over the other. For Nathan, he wants to prove that he belongs to each setting (academic and home), but is judged not on who he is, but rather how he speaks. Dialect and grammar are only a small part of the bigger picture. Growing up in an innercity area, Nathan feels a deep attachment to his home. Like Nathan, during my time as an undergraduate and graduate student I did not want to change who I was; and that my home culture was represented in every way, so I made sure to dress how anyone at home would dress and I made sure to speak in an intellectual manner when I spoke with my professors. I did this all to prove that, as did Nathan, that we are not "city hoodlums" and we able to articulate our thoughts in a meaningful manner. However while doing to this to prove our selves in the academic setting, our reputation with our home culture suffered. Nathan describes the arguments he has with people back home:

I grew up in the Latino / Mexican American community...so, more often than not, I would get kind of judged that I was being a sell-out to our street culture that we 
grew up in. Or that I was trying to mainstream myself and get myself into the circles of mainstream corporate America, and that I was being a sell-out [to] our street culture, so these accusations were often addressed to me, and so there were always in the back of my head that I needed to prove that I'm studying Social Sciences, that I'm studying [this] for us, and I'm not doing it to mainstream myself, or to escape myself from inner-city poverty. How can I explain to them that I'm doing this for us when ya know my life is completely different? I'm living the college life, where I'm surrounded by parties and the good life and good food and conferences. Meanwhile they're still starving and ya know still doing what they could to make a living day to day. So ya know it's hard to balance the two when I'm being judged. They don't understand that I'm doing this for the right reasons or at least I try to (Personal interview, Nathan, 2012).

From an identity development model point of view, it seems that the overlap of place and race overlap (Proshansky et al., 1983) to influence his identity. Already dealing with the pressure of being accepted into the academic setting, Nathan was not willing to give up his non-academic identity and still struggles to find how the two will merge. His goal is to bridge his two identities which is his reason to go on to graduate school, but yet is stuck in between his identity of being a Latino at home, and being a person part of the dominant society, or a sell-out as he puts it:

I still don't know how I'm gonna be able to do it, but I got to focus on my school work right now, and I think certainly my research, what it deals with is just trying to merge the two together, to try to merge academia with street culture and to explain why is it that we live in such poverty, and why is it that we are often in 
the predicaments that we're often in, so I guess that's how I'm trying to merge the two in (Personal interview, Nathan, 2012).

Coming from a Latino community, George felt similar resistance, but in a different way. As he continued his college education, he would often return home over the summer and winter breaks. Each time that he came home, he felt a backlash my his family:

My sister and my little brother call me white boy because I went to college. When I first started at West Virginia, I came back that summer for a couple days home, and my sister was calling me "white boy," "Look at this American," and all this stuff, and I'm like, Why? Like because I don't speak [like I did before]? Like I don't use as much slang anymore? And I'm getting educated? But I mean I guess that's the perception in our community you know? First off, like I needed proof that I'm not like [the white people]. . . I need[ed] to prove harder that I'm actually Latino? But then at this point now [that I am in graduate school], I really don't care. People can call me white for all I care, if it means that I'm bettering myself and if being white is something bad, then I guess that's what I am (Personal interview, George, 2012).

As it was for Nathan, George's Latino identity was questioned as he became more and more immersed in the academic community. George was able to move on, but at the cost of choosing his academic track over the other. Although it may seem beneficial to his professional career, George was forced to give in to an Anglo orientation (Torres, 2003). Tracie noticed the changes she had undergone too, and how people back home reacted to those changes: 
I was home one day, and visited my pastors....and I was like talking to her and I was just spitting words out and she stopped me and asked me what a word meant, and I was like, Whoa. In a sense, you don't realize it because I'm in school the majority of the time [and your] vocabulary changes and sometimes what you desire to do changes. For me, it wasn't like a mental thing, like I'm not gonna be like everybody else, like I don’t care what they did...it was more like sometimes you don't realize how much you've changed until you go back to where you were... The way that you carry yourself is a little bit different, like you try to tone it down a little bit. I don’t know. That's the best way I can describe it. You don't want people to think like that you're so different, that you're untouchable, so you kinda try to take it down a notch so that people don't feel out of place...so I monitor what I say so that people don’t feel out of place...but like sometimes people don't see the importance in what you do or the effort I put forth. I don't feel like explaining this, like I'm in school and that's all you need to know, like I don't feel like sitting and having to go through it because people don't understand ... maybe they don't value it [education] , but sometimes you just gotta tone it down or else people are just gonna be in the dark and then it's not worth talking about anyway (Tracie, Personal interview, 2012).

To accommodate everyone around her, Tracie would change the way she speaks and acts depending on the situation. For Tracie, it was something she could deal with, and in her mind would have to do, in order to keep those relationships with her non-academic peers alive. Karen shared her irritations with the people back in her hometown: 
People just looked at me weird, I guess it was because I changed so much since high school, but I thought it was a good thing....I mean college is like the norm now. I don’t know, it bothered me that some people wouldn't talk to me anymore, but I didn’t care, I left to prove everyone wrong, like that’s what I like to do, and they never believed in me, that I would go on to college, so now when I go back home and see that, I'm kind of like, whatever, it doesn't bother me anymore, cause I knew that what I did was right (Personal interview, Karen, 2012).

Karen's feelings of giving up on others display the hardships that McNair scholars go through everyday. For those like Karen, being a first generation student, meant dealing with a family population that do not know a lot of college. The WVU McNair scholars want to keep in close contact, and want to keep those close relationships with friends and family outside of academia. They really try to bridge the perceived differences between the groups, but cannot find common ground. The McNair scholars find it harder and harder to relate to those, especially friends and family who did not go to college. It seems as if an academic identity caused non-academic people to shy away from the scholars. Travis shares his frustrations when talking about those in his hometown:

Even my own friends, really close friends that haven't actually gone on to do any college or any school beyond college or anything like that and who didn't do very well in high school, but were very good friends of mine, there are some of those [people] that I feel that [the] more and more that I'm in school, there's more of a widening [gap] between us because I am more educated than them, and even if I respect them just as much or love them, they still feel that we're different. I don't 
know. That I guess is disappointing...And so if they start to think that they're better than you or you're better than them, even if you don't feel like that, even if you feel that what I'm doing is something you could do if you chose to do it, and I still respect you and think you're smart, [yet] It doesn’t [seem to] matter” (Personal interview, Travis, 2012).

Here he expresses that these people are important in his life, but is well aware that somehow he is viewed differently, even though that is not what he intended. He goes on to say:

You put yourself, through educating yourself [and] you have [to] put yourself on a different level and in a different life than they have, so you stop being more of their peer, and you start being someone different who used to be a close friend. And it's really disappointing but I think it's worth it. I mean I love these people, but I want to be where I am, and I think they're still happy for me, but they just can’t relate to me anymore. (Personal interview, Travis, 2012).

The changes in the relationships between Travis and his friends is something he struggled with, but realized that he wouldn't change the person he was becoming because that is what he set his mind to and was set on getting there.

Although all the McNair scholars have a goal of going on to pursue a Ph.D., they soon realize that tough choices lie ahead. As they become more and more immersed into an academic culture, they begin to realize the sacrifices they must make. For some they decided to leave all those behind and challenged their academic identity, while others made arrangements within themselves so they keep those relationships alive. 


\section{Is There a Transformation That Takes Place}

The WVU McNair program does do a really good job in giving these students skills needed. Through the rigorous training that starts in the summer research experience, and concluding at their graduation banquet, scholars are submerged into the academic community. During this process the program prepares them following through with what was promised from the beginning; the scholars learn: research writing skills, data analysis skills, presentation skills, proper etiquette, dressing professionally, GRE math and verbal, cultural exposure through various events, networking skills, testing skills, and how to communicate effectively. All of these skills and talents gained slowly transform these scholars into individuals. The following section addresses the final research question: Is there a transformation that takes place during or after the student's involvement in the program?

A transformation of individuals is complex because there are not moments that define when a person has transcended, but rather a process that they go through. All WVU McNair scholars spoke about the new skills and knowledge they gained with the program, but what really matters is was their own personal views of how they were affected. The theme of validation describes key moments for these scholars during their journey. Katy found a voice amongst other people, and in the process felt what it is likes to included in an academic setting:

It felt really nice that people was recognizing what we were doing as scholars...it felt like you accomplished something having it published in a big conference magazine...its not something everyone gets a chance to do, so it felt good...I felt 
scholarly and academic, something I did not feel like in the beginning (Personal interview, Katy, 2012).

Karen reflected on a speech that she had given prior to graduating:

I never imagined that I would be giving a public speech, I mean you remember way back when I first started...and I remember [the staff] coming up to me saying “that was a great speech...” It meant a lot to me, cause for me growing up I didn’t have any like role models, and now I look at myself as one... when I go home I try to talk to as many of the high school students as I can...in fact my old teacher just contacted me and said if I could come into the classrooms to talk...It's a great feeling, being wanted by others, and when I look back I think the McNair program had a lot to do with that...with me becoming someone that I never though I would be (Personal interview, Karen, 2012).

Karen's reflections helped her to realize that she was come a long way, and being a role model to others was the most important thing. With her new role, she felt like she could now go back and influence change in her hometown.

Nathan describes the moment he felt like he finally made it:

This was really moving for me because I don’t have any ya know I never really pictured myself as a scholar in my life. This is when it really hit me. When I got a note from some woman, she said she was she saw me on the manual, and she came to see my presentation. She was like from Iowa or somewhere crazy. I don’t know what state she went to school, but I know it was somewhere out there, and she came to see me specifically and she said she loved my presentation. So that 
was a moment ... I felt like, “Wow, I’m a scholar I guess” (Personal interview, Nathan, 2012).

Having someone seek out his research was important because it not only validated him as a scholar and researcher but also that his research is actually important and people care about it. For Nathan, his research is his personal struggles dealing with his two contrasting identities as a scholar and a inner-city Latino. So validating his research meant that his own struggle was recognized by others, and for him that was really powerful.

At the national conference, George felt the same validations being recognized for his achievements:

...[it] felt like my professional career was going somewhere, and I wasn’t gonna be another statistic. It was kinda like an eye-opening experience, where you actually see yourself as a true scholar. I definitely felt like I belonged there. I mean just reading my abstract and comparing it to other people’s, because that's another thing I forgot to tell you that at the beginning of the McNair program, I wasn’t sure I belonged there because I was not the straight-A student. I was a B-student, who had a lot of drive, and everybody else was straight-A students but I didn’t. So at the beginning, I felt like I maybe didn’t belong or something like that. When I saw my name there in the booklet, I felt like yeah, I do belong here, and I can do this stuff (Personal interview, George, 2012).

At the conference George discovered that for him it was all worth it. Having doubts about himself, being doubted by others, all came to halt once he seen his name. When scholars were able to reflect upon their past learning experience, they started to notice 
that they are no longer objects of history (Aronowitz, 1991). In George’s case, when he realized that he was no longer a statistic, he allowed himself to enter the academic community. Tracie found not just her academic and professional skills were developed, the program also affected her outlook on life:

I think so I did go through changes, and I think part of it is like they helped me believe in myself more-so than what I did before, like coming into McNair. I think that they helped develop like a sense of determination and confidence, which carries over not just in academia but just in you know life, when you're ready to give up, you feel that tug or like push that says, come on you can do it. You know what I mean? I just kinda feel like there’s a sense of confidence and a sense of ... I don’t know just being who I am and being happy about who I am that I didn’t have before. But I think, through training, even if it was that I learned to do academia is now it’s something that I carry in my everyday life (Personal interview, Tracie, 2012).

For others, they did not feel like a new individual, or changed person, but during the ending of the program and reflecting back, they did confess that although they may not that transformed individual, that academic scholar they strived to become, they note that they taking the right steps and that McNair helped to accomplish that. Lisa noted after the presenting at a national conference "I felt like I was starting off, like it was a stepping stone, to help get me where I want to be....but right now I still need time” (Personal interview, Lisa, 2012). 
For others, it was in graduate school, when they found it. Travis who is now a doctoral student recalls his time as an undergraduate student. Wanting more from his mentor relationships. He finally got what he wanted, and felt like he was acknowledged for his intellect. Describing his relationship with his doctoral mentor Travis said:

So I feel like I have a more personal relationship with him. In fact it's weird to call him by his first name. That was the weirdest thing I guess going from undergrad to grad school is that all of the faculty even in you classes well not in your classes but all of the faculty you work for that you work for have you call them by their first name. You're training to be their peer, and that's definitely a weird different relationship. So, I guess comparing the undergrad mentor to the graduate school mentor, I feel like now it ... I feel like as an undergrad he knew that my goal was getting into grad school, so it was a professional relationship. But now were working together on a project, and he encourages ideas out of me and he lets me have a little more free reign on my project, so I appreciate that a lot...it's nice because my opinions and my ideas are important and valid, and he doesn't dismiss them. And that means a lot to me that my ideas are not dismissed outright (Personal interview, Travis, 2012).

All WVU McNair scholars experience changes during their time with the program, whether it changes them as a person is really up to them. Past research (Baness, 2011;Beal 2007; Chatman 1994; Derk, 2007; Esler 1998, Ford, 2011; GallagherTrayhan, 2010; Grimmett et al., 1998; Olive, 2010; Willison \& Gibson, 2011; Wyre, 2011) have already shown that McNair programs provide the scholars with the tools and skills to go on the graduate school, and that these skills they gained during the program 
was helpful (McCoy et al., 2008) but through the WVU scholars experiences we see that other factors come into play and influence whether or not these students will go on. 


\section{Chapter VI}

\section{Discussion}

As staff of the WVU McNair program, we want our all of our scholars to get into graduate school and get a Ph.D. We do everything within our power to make sure that scholars have everything to get there. From the moment we accept students into the program, there is a genuine belief that each and every one of the scholars are or will become Ph.D. material. With all this being said, we would all be lying if we truly believed that every one of our scholars would accomplish this task. Each year scholars graduate, some leave already being accepted into other programs, some decide to take break, and others seem to burn out or not posses the desire to pursue higher education.

All participants in the study are already in a graduate program, or are in the process of getting in. The data set may seem biased in this way, but the main focus of the research was to look at the experiences of the McNair scholars during their journey to graduate school. Even though all were successful in getting into graduate school, each WVU McNair scholar was tasked with a different challenge. The research suggests that all participants in the study gained the skills necessary for graduate school, which they absorbed during their time with the program. The process of assembling a research proposal, conducting the research, presenting the research, and completing a final report provided the scholars with the research experience desired by graduate schools. On paper the WVU McNair scholars usually has the requirements to get them into a graduate program. Having a combination of a cumulative grade point average of a 3.0 or higher, competitive GRE scores, a polished personal statement, and research experience make a competitive graduate students application. From this standpoint, I can see why McNair 
scholars enter graduate school as higher rates than non-scholars, but do not understand why so many are dropping out with the first three years of their graduate program (Seburn et al., 2005). This research does not address the specific question of why McNair scholars drop out, but rather provide their personal stories of struggles, and achievements that allow them to get to that level. Three of the nine participants are already in graduate school, and seem to be doing fine. However if we try to understand the scholars, through their conversations we can see how much of a struggle it was just to get into graduate school, and if we can understand that, we can begin to think of reasons why other McNair scholars may not be able to handle the external pressures (or internal) that seem to force them out of graduate school. The main point of this research was to look at what it is like to be a McNair scholar, and how the program affects the scholars. The following two research questions provide a glimpse into the experiences of the WVU McNair Scholars: 1.) How does the WVU McNair scholars program affect the student participant's identity? and, 2.)How do the services provided by the WVU McNair scholars program affect the student's sense of voice and space?

\section{The Effects of the McNair Program on Space}

During their time with the program, the WVU scholars gain new skills and knowledge, that all benefit their academic abilities giving them a firm background in research. As these students adapt, they begin to make changes in: the way they speak, their behavior, and mannerisms. Although it may also be attributed to the changes students go through in college, the scholars here are presented with stresses that affect their personal lives. Following Edwards (1993) guidelines on ways to support minority students, the McNair program provides the structured environments, support, and 
services that is critical to the development of these scholars. The demands of the McNair program, ensures that these students do not get a watered down version. The McNair program treats them as graduate students by demanding the very best from these students. Although students come from different disciplines, all are required to gain a substantial amount of knowledge in conducting scholarly research. These program expectations are clearly explained to students, and encourage them to understand their decisions in going to graduate school. The demands of the program are alleviated by the services that students need. Services such as the research training, GRE training, and subject tutoring are some of the services that students found most useful, which was found in past research (Derk, 2007; Grimmett et al., 1998). As mentioned earlier, it is not the set of research, academic, and professional skills scholars gain that I want to focus on; but rather focus on the other factors that contribute to their identity formation.

The research highlights the experiences of the scholars outside of the university. These stresses are what drives or hinders the scholars from going on. In this research students like Travis, George, Tracie, Jane, Dianna, Lisa, Katy, and Karen were all able to balance out the negative support they received outside of the McNair environment with support they gained inside. For Travis and George, it meant not talking to those who did not support or understand their decision to go to graduate school; while others were content in altering their behaviors to adapt in both their home and school culture. On the other hand Nathan, still struggled to find the balance between the two. Not wanting to leave those at home behind, he still contemplates about how he can bridge the gap between his home and school cultures as he begins his graduate school career. 
The WVU McNair program filled the support role that was absent from the scholar's lives. Through the summer research experience, ORIN 493-I, cultural trips, and professional conferences, the WVU McNair program was able to provide an intimate space for the McNair scholars to grow closer. Among the company of others, the scholars could be with a unique group of individuals not commonly found around campus. The scholars found that they all came from similar backgrounds, and all faced similar challenges outside of the McNair space. Feeling safe within the group, the scholars could engage in deep and authentic manners, which helped to create a community (Bickford \& Wright, 2006). The support felt from this community allowed scholars to find meaning within their lives, and self reflect on what is really important right now in their lives. Specialized critical social theory (Soja, 1989) helps to explain how social constructions of knowledge and ideologies fill place such as a Black inner city (Gruenewald, 2003). The same phenomenon that applies to Black inner cities holds also true in the McNair program. Within the walls of the McNair program, scholars are reintroduced to knowledge and ideologies that help empower them as individuals. Disregarding the negativity of all social constructs that exists outside of McNair, the scholars find in this space, somewhere to grow and flourish as McNair scholars. From this, I see that the WVU McNair program provided a space that affected the scholars' identity is a positive way.

\section{The Effects of the McNair Program on Voice}

Before the scholars are able to connect with each other based on their backgrounds and past experiences, they find that the struggles they face as McNair scholars initially brings them closer. Having to go through the six-week summer research 
experience is a true test of their abilities. From their reactions, as well as my own observations of them, the summer research experience is when they realize that they are not alone. Almost all the participants doubted their academic abilities, but soon found that everyone was on the same level, and that everyone was just as stressed out. Within the McNair program, they found the program to be challenging, but through the support of the staff and their peers, they began to see that the program was much more than a training ground for graduate school. As they began to grow closer, they began to identify with the personal stories of their peers, and soon enough they realized that they were not so different after all, especially when it came to their lives outside of the McNair program.

Not having the expected support or understanding from those outside of McNair, posed a real threat to the development of WVU McNair scholars. Without the support, these scholars may have felt as if higher education was not an option for them. For scholars in this research, coming from a disadvantaged background made the road to graduate school really difficult. For some like Nathan, George, and Tracie, the education system was never a place they felt comfortable in. Especially for these three, they felt as if there was a need to conform to the dominant society (Graham, 2005). Feeling a need to adapt to their surroundings all of the WVU McNair scholars made adjustments and alterations to their behavior, mannerisms, and even identity to try fit with either their home or school culture. Again the stress that comes with actively trying to do this grows tiresome. In the McNair program, at WVU and at the national level, the scholars got to meet others who had the same experiences. By discovering that others not only have the same experience but also the same passion to go on, the WVU McNair scholars found a 
voice. Knowing that others share the same experiences gives the scholars a sense of comfort, and also a sense of meaning. As members of underrepresented minorities or first generation and low-income; the WVU McNair scholars, who felt like a silenced community began to take back their identities, they found meaningfulness and legitimacy through the connections they built, with this, they empowered them selves to start taking control of their lives (Belenky et al., 1986; Freire, 1993; Gilligan, 1982). Finding their voice, the scholars see include themselves in the learning process, and as members of the community and no longer objects of history (Aronowitz, 1991), or statistics expected to fail like the rest that not a part of the dominant society.

The WVU McNair scholars also found a voice through the publicity of their research. Presenting at the national conferences, having their work published in conference journals, and symposiums all contribute to the scholars voices. Being able to see their work on a document was really powerful for the WVU McNair scholars. For students like Nathan, George, Tracie, Lisa, and Katy it was those moments of having something tangible that helped to legitimatize and hold their place in an academic community. The McNair program provided students with opportunities to showcase and find a voice within the academic community, enabling the scholars to take action in molding their identities.

\section{The Effects of the McNair Program on Identity}

Seeing how the McNair program not only provides scholars with a space to grow, I found that the space created, eventually becomes a sense of place, creating a community for these scholars. Within this community the scholars find a voice, a voice that represents their past, their present, and their future. A voice that they are able to identify 
with, a voice that lets them know that they are not alone, and others are out there who see the world as they do. McLaren (1991) reminds us when shaping a student's identity; we need to be sure that all diverse cultural realities have a voice. To understand how the program affects the scholar's identities I needed to first understand the scholars' identity.

The WVU McNair program was able to provide that space, where the scholars could find their voices. As each scholar makes the transition or was in the process of becoming a scholar, it was important that their stories were not left out. Scholars needed to know that they are not alone, that they are not being a "sell-out", or mainstreaming themselves, or becoming white. They needed to hold on their identities, the person they were before the program, but some how build upon that as they began to adapt a scholarly role. This is clearly evident in the Nathan's story. Nathan was well aware of the effects socio-political effects of the dominant culture on his identity. He was trapped between his two identities. Having strong connections to this hometown, I see that his place identity plays a major role in his life, but at the same time, he striving to gain an identity as an academic, a person that is accepted in the college community. He faces a constant internal battle with who he wants to become and who he was. Not wanting to be a "sell-out" Nathan tries to convince his friends from back home that he is indeed going to better the community, but his plea falls upon deaf ears. George felt the same struggle, but instead of having an attachment to his home, his battle was with being a Latino. Just as Nathan was criticized for being a "sell-out", George was called out for being more White than Latino. Unlike Nathan who tried to bridge the two, George found it easier to just accept that he was considered White and moved on with his life. As he got into graduate school, he admitted at first that he tried to be more different, and eventually 
found out that it was perfectly ok to be himself, and that being a Latino was not a bad thing after all. In both scenarios, I see that many things like race, place, and professional identities all influence the scholars' identities. For Lisa and Katie, the identities as African-American females, their identities as females posed as a barrier to continuing their education. As females they not only had a commitment to their family, but also coming from impoverished neighborhoods they were also pressured to find a job as soon as they graduated. In their stories, their identities of gender, places and race all come together to pressure the scholars, and prevent them from going to gradate school. Other scholars who participated found that because they had a firm support group, and already possessed the confidence and security with their identity. It is the scholars like George, Nathan, Lisa and Katy, that may sometimes fall through the cracks and not go on because the pressures from contrasting identities.

During this journey to adopt an academic identity, these scholars had to make sacrifices, which came in the form of giving up on other people who did not believe in them. Instead they chose to embrace people that understood what it was like, and that supported them no matter what. In the end, the McNair program and its community of members are the ones who were able to support them as they faced those ultimatums in their lives. It is through this indirect relationship that the WVU McNair program affected the scholars' identities. No matter what was going on in the classroom, the scholars could always find a home within the McNair program. The WVU McNair program, through its support system from the staff and students helps to give a positive influence on scholar's identities. With the McNair program, they found a new support system, one 
that included people who understood the journey, the struggles, and the sacrifices that scholars make.

\section{A Network of Support}

At the national McNair conferences, the WVU McNair scholars, as well as those from the other programs begin to see that even though they all come from different geographic locations, they are still able to connect at an intimate level. Even though they never met each other, they feel as if they known each other their whole lives. WVU McNair scholars leave the conference, with not only professional contacts and colleagues from other universities, but with friends who share a common bond, which is the McNair program. The refreshing feeling of knowing that others are out there leaves an impression on the scholars' minds. It is through this lasting impression that they scholars start to imagine what the other McNair scholars are like. Scholars like George, Nathan, and Lisa found it exciting to know that their graduate school institution had a McNair program, and all made an effort visit, hoping to find a group of scholars similar to those that they left behind at WVU.

Benedict Anderson’s (2006) term “imagined communities” describes this connection that the scholars feels with others whom they did not yet meet or hoped to meet. All of the McNair scholars have connect in ways that others outside of the program do not really understand. To illustrate this I use myself as an example, where my imagined community consisted of people from Hawai‘i. In college I met many other people whom I never met, but somehow gained an instant connection with people from Hawai`i. During the conversations I had, I began to speak pidgin English (a common dialect used in Hawai`i), laugh, and find joy in knowing that I found someone else who I 
could relate. These communities are imagined because I never knew these people, but in our minds we both bring what we believe Hawai'i represented to us. Whether it is an accurate portrayal or not, it provides us the members of the imagined community a space to connect and reflect on our imagined spaces. The feelings experienced is hard to explain, but is very similar to what the McNair scholars have. An imagined community that provides a sense of support no matter where they are. Through an imagined community, the support system they have is no longer restricted to the physical boundaries of WVU, or national McNair conferences. Through the power of imagined communities, the WVU McNair scholars is able to carry with them their memories of how McNair was such a great experience, the joy of speaking about it with someone else is that is needed to bring those memories back to life.

\section{The Next Step for the McNair Scholars}

Over coming the struggles and making it into graduate school is not the final hurdle for the scholars as well as myself. It was in my doctoral program, where I found my identity. It was one that rooted me to my core values and beliefs and also allowed me to interact in an academic world. My story is one that is very similar to all the participants on the study, as well as other McNair scholars. Through our conversations, we try to paint a portrait of our educational journeys. As we shift through stages of our own personal identity rooted in our history, background, and culture; and into a group identity with the McNair program, and lastly how we adapt to this new professional or academic identity. For me, I feel I have found balance amongst all identities that I carry with me. Through my experiences in higher education, I have had time to take a step back and reflect upon who I was, who I am, and who I am I becoming. My story speaks 
about the phases I have gone through while trying to belong in higher education, it expresses my struggles to fit in, and the constant questioning of my identity. The WVU McNair scholars relive these same stories during their journey: like Travis I had to leave friends behind as I stayed in college longer; like George I considered myself to be White; like Nathan I was stuck between my individual (home) and academic (school) identity; like Jane I was never a "smart student"; like Katy I knew what it was like to be alone in the process; like Lisa I felt my family did not recognize my academic abilities early on; like Tracie I had to become conscious of my behavior at home; like Dianna I found a support system that was like a family, and just as Karen did, I overcame obstacles by wanting to prove everyone wrong. The stories shared in this research do not focus on the college process and what it takes to get into graduate school. For this research and for the participants of the McNair program, success is not measured by getting into graduate school, success was something far bigger than a piece of paper that admits you to graduate school. Success was defined by my own personal belief that I belonged in graduate school, and that others as well as myself felt I had a place there.

As mentioned earlier, I found a balance amongst my identities through a support system of people that believed in me. For me I look back and think that I was in the right place at the right time. I know all individuals in society cannot reproduce my circumstances, which is why I see the McNair program offering the same support that enabled me to discover my identity. Looking back at the first two research questions (How does the WVU McNair scholars program affect the student participant's identity? and how do the services provided by the WVU McNair scholars program affect the student's sense of voice and space?), I find that the McNair program fills the void the 
absence of support that the scholars needed from those around them. Through the WVU McNair scholars' responses, we see that the most important factors were the role of support, and how McNair became a group of people who they could trust becoming like a second family to the scholars. It was here that the students found a foundation, a place to help build a new identity. A home amongst peers where they were accepted and not judged based on who they were, who they are, and who are they becoming. The same treatment the scholars received here within the McNair program is the same treatment I felt I got from my support group, and through them, myself as well as the scholars begin to feel a transformation. Looking at the last research question on transformation, the research highlights some of the perceived transformations that took place. Although not all scholars had undergone a transformation, I believe they found a place within McNair that they will always look back to, to lean on. Transformation takes time, and does not happen all at once, it is a process.

Navigating through personal identities and newly formed professional identities, the participants of the WVU McNair program found a group identity within McNair that allowed them to bridge the gap between the two contrasting views. They try to hold on their personal identities, which are based on their history, ethnicity, home, family role, or culture. While doing this they try to adopt a new role, a role of being an ideal graduate student, a professional identity within the academic setting. These two identities often do not agree with each other and in the end, the strain can sometimes cause one identity to succumb to the other. To deal with these struggles, the participants form a bond, thus creating a group identity, the identity of the McNair scholars, a world where all of their identities are accepted and shared with one another. This group identity becomes the 
support system, so that the scholars can discover their identity. The same identity as my own, in the sense that it helped to anchor me when moving toward my professional identity, as well as my way of life. The research highlights that for these students, getting into graduate school is just a perk. The real success for these students comes from discovering that they are able and that they do belong in a higher education setting. Success for these students is gaining an awareness of the conflicting identities and learning to live within the contrasting views. All of the participants in this study may not have found this yet, but have begun the process of finding this identity.

\section{Implications}

The academic community of scholarly researchers is culture in itself, one that the McNair scholars are not well aware of at first. Within this culture, it is assumed that tone must present themselves in a certain manner to gain access which include: being able to articulate your point of view, using intellectual grammar, dressing professionally at conferences, etc. All of it challenges the identities of those who were already not aware. These McNair scholars are from underrepresented populations, and in a way, we the McNair program challenge their pre-conceived notions. We train them to become scholars so that they will be able to change the face of academia

I am not saying we are forcing people to adapt new identities, but I am saying we need to be wary of what lies under the surface. Sometimes even I get caught trying to play the "ideal" role of a member of the academic community and have to questions myself: Whose best interests does it serve? Is it mine? Or is it the scholars? There needs to be sensitivity and awareness for what these students are experiencing. As educators, we should not force people to adapt to a new culture, without helping them to understand 
their own. We need to encourage our students to embrace their past, histories, cultures, and values. We should not focus on stripping down a person so that they may fit in, instead find ways to accommodate or have the students become aware of scenarios and situations where they must obey and follow the rules. Event though these scholars, come into the program as high achieving students who are very intelligent and highly ambitious individuals, we must remember that each bring with them their own personal stories, and remember that they are from underrepresented populations, and if it seems that everything together from an outsider point of view, we must look under the surface to really see what is going on.

One reason qualitative research is an effective method is because it gives voices to those silenced individuals (Coffey \& Atkinson, 1996). However qualitative research is not looked upon on the same manner as quantitative research. The research presented here not only contributes to the past literature of McNair scholars and how minority population experience college, but it also helps to establish themes and questions that can be used in quantitative research methods. Quantitative surveys methods, which usually ask participants yes or no questions, or have the participants rate a question; are limited by the questions they pose to the audience. Effective surveys will use try to use to questions that encompass everything that surrounds the topic. The themes that came out of this study: challenging structure, support, uncertainty, barriers, inclusion, and validation, help to understand the WVU McNair scholars experiences and through their conversations we began to understand how they felt throughout the whole experience. Applying these themes to future research may help to understand how others deal with the external pressures while going through the process of going to graduate school. 
The WVU McNair scholars whose stories are shared here were able to help me in understanding as well as validating my own educational journey. A lot of their experiences I have already gone through and faced in my past. Being to able to know that others like myself exist, helps me to reflect on my journey, and feel comfortable with where I have gone with my life. The research presented will also be able to contribute to the identity development of future McNair scholars. Engaging in a critical narratology (Haymes, 1995), these past scholars are able to share their personal stories of triumphs and tribulations with the future McNair scholars. The new scholars are able to find in these stories a voice which guides them. New scholars will be bale to disregard the outside world, ignore the past social constructs of knowledge created by groups who do not support them. Within this context, future scholars can identify with these counterstories that allow those people who was once considered outsiders and are now members of the academic community. The voices of the scholars who participated in this study live on within the texts. Their stories help others, like myself, know that just as they were able to overcome obstacles, so can you. Their stories give voice to the future scholars, who may experience the same struggles as they have, just as I have. Through the sharing of my story and the scholars' stories we not only empower ourselves but all of those who read it. Using critical narratology, the WVU McNair scholars may find that writing journals that speak about student life inside and outside of the program supports them in numerous ways, and should be used in future program activities.

The research also highlights a growing concern for the scholars once they graduate. In the interview, the scholars commented on how important the support was while in the program, but as they graduated and moved on, they found that even though 
they could still contact the WVU McNair staff, it was not the same as being in close proximity. Having the support system from those in the McNair program was the most recognized characteristic of the program that all scholars described to the best part of the program. Willison and Gibson (2011) voice the same concern about the McNair scholars. I too believe that giving them the support, and teaching them how to find the support does not equate to scholars finding what they need. Because getting a doctoral degree is an optional choice and not as required as a Bachelors degree in today's society, I doubt that the U.S. government can create programs similar to McNair at a national level. As members of the McNair community, we the staff should be able establish a network for our students, so that they may use other members of the McNair community as support. I am not asking other programs to donate their time, money, and services to our students, but rather asking that they show support for our students. The support can come from introducing them to others in the academic community in schools, introducing them to current McNair scholars, or even taking the time to see how they are adjusting to the new environment. Simple deeds such as these, that include the scholars in their new university homes, go a long way for the McNair scholars. As the research suggests, there are many people in the WVU McNair scholars' lives, who do not understand why they are going on. To prevent them from feeling alone, these scholars need as much people around them that understand and fully support them on their future endeavors.

\section{Future research}

As research begins to shed light and provide insight to previous questions, the research also creates more questions in the process. The research focused on the experiences of the scholars and journey to graduate school. As I begin to talk to scholars 
about their experiences at the national McNair conference, I began to feel that each scholar had a unique experience. At first I thought that they might feel out of place because of not belonging to certain ethnic group, but after interviewing the participants ethnicity had little to do with their experiences. In fact all scholars identified with the bigger picture of all belonging to the same group, a community of minority students. As I thought about this, I thought about one of the reasons that influenced the research was came from the question: How do we view diversity?

The term diversity was mentioned as the starting point of this research. Mission statements across United States tossed around that buzzword hoping to attract people to their respected universities. Diversity is a word that can often be overlooked for its definition. The term diversity really means different, but yet somehow in my experiences is associated with minority groups. I have been involved in many instances where I was invited to speak or be a part of panel dealing with the issues of diversity around a university campus. When I get there I find it funny that the room panel or audience is filled with members of racial minorities and members the LGBT community. I find it funny because the term diversity means different, yet this room or panel is filled with minorities, who may be different from each other but are able to find common grounds as part of larger picture of being the minority group on campus. Therefore, diversity amongst minorities is really not diversity at all. In the research, Travis talks about this issue finding it counterproductive to have minorities present to each other in a conference. In his mind, Travis, believe that things like race and culture shouldn’t matter anyway. I agree with Travis and how he feels about the topic, but I also feel that having conference solely for McNair scholars helps them build up to bigger conferences. 
However, I do feel that future research needs to look at how we practice diversity within educational settings. Diversity should no longer be a checklist of ethnic minorities such as African-Americans and Hispanics. We must recognize that diversity really means different, and different may include members of both the minority and majority populations. For example diversity panel discussions should not only be limited to African-Americans and Hispanics because they are majority members of a minority group. We must also look to include other minority groups, which include LGBT, religious groups, and even members who are White, should be able to participate. Diversity only becomes real and authentic when everyone involves can clearly see differences between all groups. The WVU McNair scholars identified with the minority group in general. They looked past the issues of race and found that all McNair scholars were the same. From this point of view, it may seem that those in McNair are diverse in terms of how they look but in terms of their background struggles, and hopes for the future, they are in fact really not diverse at all. As educators we need to not get caught up in the word diversity and prematurely associate it with ethnic backgrounds. We must look at word diversity, and its use actual meaning- differences, when implementing them in various programs and activities. When we think of diversity, we must think of white, when thinking of black, we must think of straight when thinking of gay or lesbian, and we must think of ourselves and how we fit in, and than find those not included in out definition of self, and include them as well. By ignoring the obvious differences between groups, and only focusing on minority, we in a way are contributing to the separation of minority and majority systems. 
As declared earlier, those who participated in the interviews for this research were either already in a graduate program, or have been accepted and will be going to graduate school. As Edwards (1993) pointed out that ones in college were the "lucky ones", I find the same thing to be true of those that participated. Although the research presents scenarios of WVU McNair scholars and their struggles, these are also the students who were able to make it to graduate school. We are not sure if they will succeed, but nonetheless are taking steps in the right direction. Future research needs to look at those who decided not go on for whatever reason. By understanding why McNair scholars do not go, we can begin address changes that could be made with the program's structure to accommodate these scholars.

As we focus on getting these populations into graduate school, we must not forget to also look at their plans post graduation. As mentioned in chapter one, the McNair program's overall goal is to change the face of academia and although it seems they do a good job of getting students into graduate school it is not enough. In 2006, approximately $10 \%$ of all academic employers were made up of underrepresented minorities, and less than $8 \%$ of full time faculty are from underrepresented minorities. Underrepresented minority populations were defined as blacks, Hispanics, and American Indians/Alaska Natives (National Science Foundation, 2010). The end goal is not to get these students into graduate school, or to even have them graduate. Rather the goal should remain the same, which is to change the face of academia. So far the numbers suggest that they there is still a lot to do in relation to the ethnic diversity of the faculty.

Lastly, research needs to look at the future of the McNair program. Recent budget setbacks have forced the U.S. government to take away funding from future 
McNair programs. The next grant competition will be able to award approximately 127 McNair programs (Federal Register, 2012), and currently there are 200 McNair programs in the United States. The new guideline for the McNair competition gives a preference to colleges and universities who place a priority on Science, Math, Engineering, and Math (STEM) students. As we move forward we may see a shift in what McNair is, and what it represents. During my years with the WVU McNair program, we had only a handful of students from STEM majors, and most of which already came in with research experience and academic skills. It was the students who came from the social sciences, students like Nathan, who tried to use their research as ways of connecting his home and school culture, rather than a way to escape it all. As the program shifts toward a focus in STEM fields, it would be interesting to see if those future students would still experience the McNair program as those from non-STEM fields.

\section{Now that I know who I am, I find a greater sense of purpose}

As I conclude my research I find the words of Parker Palmer fitting, in describing not only my journey, but also the journey of the WVU McNair scholars. In his book Let your life speak: Listening for the voice of vocation, Parker Palmer (2000) describes the word and context of vocation:

There maybe moments in life when we are so unformed that we need to use values...to keep us from collapsing...trying to live someone else's life, or to live by an abstract norm, will invariably fail- and may even do great damage...Vocation does not come from willfulness. It comes from listening. I must listen to my own life and try to understand what it is truly about- quite apart 
from what I would like to be about- or my life will never represent anything real in the world, no matter how earnest my intentions.

That insight is hidden in the word vocation itself, which is rooted in Latin for “voice.” Vocation does not mean a goal that I pursue. It means a calling that I hear. Before I can tell my life what I want to do with it, I must listen to my life telling me who I am. I must listen for the truths and values at the heart of my own identity, not the standards by which I must live- but the standards by which I cannot help but live if I am living my own life. (pp. 3-6).

As a high school senior I dreamed of becoming an architect, later on as a sophomore in college I wanted to be a clinical psychologist, in my Master's program I thought I was going to be an educational consultant. All of these “dream jobs” have always been influenced by what I thought was "professional" jobs, jobs that would make me "somebody" in the world. It was during my doctoral program, that I finally took a step back and observed my life, the course it has taken, and the point where I currently am. I compare myself often with the scholars' journey and hope that they too will be able to listen to their own life, and understand where their path is taking them. Find an identity, one that will anchor will you down as you move forward in life. As you begin to understand your own life, you will then be able to fully immerse yourself in the worlds of others, no matter how different they seem to be from your own. 


\section{Appendix A}

\section{Appendices}

Hi, my name is Thomas Keopuhiwa and I am conducting a research study under the supervision of Patricia Obenauf, Ed.D. Professor in the College of Human Resources and Education at West Virginia University. The purpose of this research study is to help understand minority and first generation students' journeys through post-secondary education; in particular I am looking at the experiences of West Virginia University McNair scholars. My research will highlight two main concerns: 1) How does the McNair program affect a student's identity and 2) if students perceive a transformation that took place after completing the program. I would like to invite you to participate in an interview as part of this study. Your participation is entirely voluntary and your identity will be kept confidential. The interview will be recorded (via audio recorder) in order to accurately represent what you say. Our interview should for last for no more than 45 minutes. On the bottom is my email address, if you want to participate in the study please email me and we can set up a time for the interview, which will take place in the McNair office room $102 \mathrm{~A}$. Before choosing to participate in the study I want to make sure you understand the following:

- You must be 18 years of age or older to participate.

- Your participation is entirely voluntary, you can choose to stop the interview at any time and you do not have to answer any question you do not want to answer.

- Your responses will be kept as confidential as legally possible. Your name will not be attached to notes from this interview or to transcribed data, and the audio will be erased once transcription is complete. At no time will your name be revealed during reporting.

- Your class standing, grades, or job status will not be affected if you decide either not to participate or to withdraw.

- Besides volunteering your time to participate in this interview, there are no more than minimal risks for you to participate in the study.

- West Virginia's University's Institutional Review Board acknowledgement of this project is on file.

Thank you again for your willingness to participate in this study.

Sincerely,

Thomas Keopuhiwa

Thomas.Keopuhiwa@mail.wvu.edu

Patricia Obenauf, Ed.D.

304-293-4376

Patricia.Obenauf@mail.wvu.edu 


\section{Appendix B}

\begin{tabular}{|c|}
\hline Interview Protocol \\
\hline $\begin{array}{l}\text { 1. Tell me a little about your goals and aspirations prior to joining the McNair } \\
\text { program. }\end{array}$ \\
\hline 2. How did you learn about the McNair program? \\
\hline a. Did you ever hear about the program? \\
\hline 3. What made you apply for the program? \\
\hline a. Why did you apply? \\
\hline $\begin{array}{l}\text { 4. Try and recall the day you found out that you were selected to become a McNair } \\
\text { scholar; how did it feel? }\end{array}$ \\
\hline a. What were you excited about? \\
\hline $\begin{array}{l}\text { b. What were you fearful of? } \\
\text { c. What specific tools, skills, or experiences did you hope to gain from the } \\
\text { program? }\end{array}$ \\
\hline $\begin{array}{l}\text { 5. Do you remember the first time you were all together in the summer research } \\
\text { experience; tell me a little about what you did during that summer. }\end{array}$ \\
\hline a. Tell me about some your fears, hopes, and goals for that summer? \\
\hline b. How did you feel once the summer research experience was over? \\
\hline c. How much did you learn about research? \\
\hline $\begin{array}{l}\text { d. How much did you learn about yourself? } \\
\text { e. How did it feel to be in a class filled with people who had the same goals } \\
\text { and aspirations? }\end{array}$ \\
\hline 6. What did the term "research" mean to you prior to becoming a McNair scholar? \\
\hline a. What does it mean now? \\
\hline 7. Talk a little about the ORIN 147 McNair class; what was that like? \\
\hline $\begin{array}{l}\text { a. What things did you learn in that class? } \\
\text { b. How did it feel to be in a class filled with people who had the same goals } \\
\text { and aspirations? }\end{array}$ \\
\hline c. What things were beneficial? \\
\hline i. What else could have the class provided? \\
\hline 8. Describe some of the cultural trips that the McNair program went on? \\
\hline a. What did it feel like to have these opportunities? \\
\hline b. What did you gain from attending those trips? \\
\hline 9. Recall the first McNair conference you attended, how did you feel? \\
\hline $\begin{array}{l}\text { a. Tell me about some of the things you enjoyed, learned, or found } \\
\text { interesting from the conference. }\end{array}$ \\
\hline b. How did it feel to be in a room with other McNair scholars? \\
\hline $\begin{array}{l}\text { c. Talk about the feelings and emotions you felt when listening to the } \\
\text { keynote speakers, or interaction with anyone else at the conference. }\end{array}$ \\
\hline $\begin{array}{l}\text { d. Tell me about other experiences that were similar to the McNair } \\
\text { conference. If not tell me what made the conference so unique or special } \\
\text { as compared to other academic functions. }\end{array}$ \\
\hline $\begin{array}{l}\text { 10. Now, describe your experience when you presented at the conference for the first } \\
\text { time. }\end{array}$ \\
\hline
\end{tabular}




\begin{tabular}{|c|}
\hline $\begin{array}{l}\text { a. How did it go? } \\
\text { b. How did it feel to have other people ask questions/ or show a genuine }\end{array}$ \\
\hline interest in your research? \\
\hline c. How did it feel to tell others about your research? \\
\hline d. What did you take away from the conference? \\
\hline $\begin{array}{l}\text { e. Was any of your work published in a journal, conference booklet, or any } \\
\text { other form print? }\end{array}$ \\
\hline f. How did it feel to see your work published? \\
\hline 11. How has the McNair program prepared you for graduate school? \\
\hline $\begin{array}{l}\text { a. Besides the research training, GRE training, etc., are there other things } \\
\text { that the McNair program provided you with? }\end{array}$ \\
\hline $\begin{array}{l}\text { 12. Recall the day that you got your first acceptance letter. What did that letter mean } \\
\text { to you? }\end{array}$ \\
\hline a. Who was the first person you notified? \\
\hline i. How did the conversation go? \\
\hline 13. What did it feel like, wearing the McNair stole on graduation? \\
\hline a. Did others ask you what it was? \\
\hline 14. How does it feel, to finally be in graduate school? \\
\hline 15. Describe how the program helped you to be ready for graduate studies? \\
\hline 16. With whom do you still keep in contact with from the McNair program? \\
\hline $\begin{array}{l}\text { 17. Describe some the obstacles you face in graduate school and how you are dealing } \\
\text { with them. }\end{array}$ \\
\hline $\begin{array}{l}\text { 18. What advice would you give to students who would like to go on to graduate } \\
\text { school? }\end{array}$ \\
\hline a. What tools and skills are necessary in graduate school? \\
\hline $\begin{array}{l}\text { 19. Comparing your undergraduate and graduate school relationships with faculty } \\
\text { (and/or your current university), how are the relationships similar or different? }\end{array}$ \\
\hline a. Describe the relationship with your peers and family. \\
\hline $\begin{array}{l}\text { 20. What does your friends or family (outside of the McNair group) think about your } \\
\text { decision to go on to graduate school? }\end{array}$ \\
\hline a. Do they support you? \\
\hline b. Do they understand why you want to go on? \\
\hline c. In what ways do they support you? \\
\hline d. In what ways do you feel, they do not support you? \\
\hline 21. Tell me about your relationship with your faculty mentor. \\
\hline a. In what ways was your faculty mentor helpful? \\
\hline b. Was it intimidating to develop a research project with that person? \\
\hline c. How has your relationship developed since the program started? \\
\hline $\begin{array}{l}\text { d. What was it like to work along your mentor and/or other graduate } \\
\text { students? }\end{array}$ \\
\hline 22. Tell me about your relationship with the McNair staff. \\
\hline a. In what ways did they support you and encourage you to go on. \\
\hline 23. Can you describe your McNair cohort? \\
\hline a. How are they different from you \\
\hline
\end{tabular}


24. Who or what would you say has helped the most while being with the McNair program?

25. Tell me about some of your positive experiences with the program?

a. How about some negative experiences?

26. What were some of the toughest times or challenges you faced, while you were a McNair scholar?

a. How did you overcome them?

27. Besides helping you get into graduate school, describe some of the other things that McNair helps you with.

28. Looking back at the first day you became a part of McNair, how has the program affected you?

a. Has the program had a positive or negative effect?

b. Looking back now, do you regret becoming a McNair scholar?

i. Why or why not?

29. What else could the McNair program have offered you that would have been beneficial?

30. Where would you be, or would have been if you never a part of the program?

31. Say you have to describe the McNair program to someone who has never heard of it, what would you say to that person?

a. How would you describe the program?

32. Is there anything else you would like to add about the McNair program that we did not cover or that you feel is important? 


\section{References}

Access and Equity. (2011). Chronicle of Higher Education, 58(1), 42-49.

Aguirre, A. Jr., \& Turner, J.H. (2001). American ethnicity: The dynamics and consequences of discrimination. $3^{\text {rd }}$ edition. Boston: McGraw Hill.

Alexander, B.K. (2011). Boojie! A question of authenticity. In V.A. Young, \& B.H. Tsemo. (Ed.). From bourgeois to boojie (pp. 309-330). Detroit, MI: Wayne State University Press.

Anderson, B. (2006). Imagined communities: Reflections on the origin and spread of nationalism (Rev. ed.). London: Verso.

Anderson, J.D. (2002). Race in American higher education: Historical perspectives on current conditions. In W.A. Smoth, P.G. Altbach, and K. Lomotey. (Ed.). The racial crisis in American higher education: Continuing challenges for the twentyfirst century (pp.3-22). Albany: State University of New York Press.

Aronowitz, S. (1991). Postmodern education: Politics, culture and social criticism. Minneapolis, MN: University of Minnesota Press.

Attewell, P., \& Lavin, D.E. (2007). Distorted statistics on graduation rates. The Chronicle Review, 53(44). Retrieved from http://chronicle.com/article/Distorted-Statisticson/1985

Austin, A. (2002). Preparing the next generation of faculty. Journal of Higher Education, 73(1), 94-122. 
Baness-King, D. (2011). Journey to the doctorate: Motivating factors for persistence and completion of doctoral programs among McNair scholars. The University of New Mexico. ProQuest Dissertations and Theses, http://search.proquest.com/docview/896134503?accountid=283

Beal, R. Y. (2007). "You mean they’ll pay me to think?": How low-income, firstgeneration and underrepresented minority McNair students construct an academic identity as scholar. University of Colorado at Boulder. ProQuest Dissertations and Theses, http://search.proquest.com/docview/304887285?accountid=2837

Belenky, M., Clinchy, B., Goldberger, N., \& Tarule, J. (1986). Women’s ways of knowing: The development of self, voice, and mind. New York, NY: Basic Books Publishing, Inc.

Belenky, M. \& Stanton, A. (2000). Inequality, development, and connected knowing. In Mezirow, J (Ed.) Learning as transformation. San Francisco, CA: Josey Bass

Bickford, D.J. \& Wright, D.J. (2004). Community: The hidden context for learning. In D.G. (Ed.). Oblinger,Learning Spaces. Retrieved from http://net.educause.edu/ir/library/pdf/PUB7102d.pdf

Callejo-Perez, D. M., Fain, S. M., \& Slater, J. J. (2004). Pedagogy of place: Seeing space as cultural education. New York, NY: Peter Lang.

Capello, D.C. (1994). Beyond financial aid: Counseling Latina students. Journal of Multicultural Counseling and Development, 22(1), 28-36.

Chatman, K. (1994). A study of the university of Tennessee Ronald McNair postbaccalaureate achievement program: Factors related to graduate school enrollment 
for first-generation, low-income and under-represented college students. The University of Tennessee). ProQuest Dissertations and Theses, , 170 p. http://search.proquest.com/docview/304112025?accountid=2837

Chickering, A.W., \& Reisser, L. (1993). Education and identity (2 ${ }^{\text {nd }}$ ed.). San Francisco: Jossey-Bass.

Choy, S. P. (2001). Students whose parents did not go to college: Postsecondary access, persistence, and attainment. U.S. Department of Education, National Center for Education Statistics.

Clark, V., \& Creswell, J. (2008). The mixed methods reader. Thousand Oaks, CA: Sage Publications, Inc.

Coffey, A., \& Atkinson, P. (1996). Making sense of qualitative data: Complementary research strategies. Thousand Oaks, CA: Sage.

Cole, S., \& Barber, E. (2003). Increasing faculty diversity: The occupational choices of high-achieving minority students. Cambridge, MA: Harvard University Press.

Cuadraz, G. H. (1996). Experiences of multiple marginality: A case study of Chicana scholarship in women. In C. Turner, M. Garcia, A. Nora \& L. Rendon (Eds.). Racial and ethnic diversity in higher education. ASHE reader (pp. 210-222). Lexington, NJ: Ginn Press.

Cummings, J. (1986). Empowering minority students: A framework for intervention. Harvard Educational Review, 56(1), 18-37.

Cross, W.E. Jr. (1971). The Negro-to-black conversion experience. Black World, 20, 1327. 
D’Augelli, A. R. (1994). Identity development and sexual orientation: Toward a model of lesbian, gay, and bisexual development. In E. J. Trickett, R. J. Watts, \& D. Birman (Eds.), Human diversity: Perspectives on people in context (pp. 312-333). San Francisco: Jossey-Bass.

Deloria, V. Jr., \& Wildcat, D.R. (2001). Power and place: Indian education in America. Golden, CO: Fulcrum Resources.

Derk, A. M. (2007). Highlighting hope: An exploration of the experiences of West Virginia university McNair scholars. West Virginia University. ProQuest Dissertations and Theses, http://search.proquest.com/docview/304799189?accountid=2837

Edwards, F.M. (1993). Behind the open door: Disadvantaged students. In A. Levine (Ed.). Higher learning in America 1980-2000. Baltimore, MD: The Johns Hopkins University Press.

Erikson, E. (1968). Identity: Youth and crisis. New York: Norton.

Esler, A. K. (1998). A Texas-wide evaluation of the Ronald E. McNair postbaccalaureate achievement program. Texas Tech University). ProQuest Dissertations and Theses, http://search.proquest.com/docview/304454084?accountid=2837

Espinoa, L.M. (1995). Hispanic involvement in early childhood programs. Urbana, IL: ERIC Clearinghouse on Elementary and Early Childhood Education, University of Illinois. 
Ford, L. D. (2011). A phenomenological study exploring the undergraduate McNair program experience of program alumni currently serving as college faculty. Loyola University Chicago). ProQuest Dissertations and Theses, http://search.proquest.com/docview/871678944?accountid=2837

Fordham, S. \& Ogbu, J.U. (1986). Black students' school success: Coping with the burden of acting “acting white”. Urban Review, 18(3), 176-206.

Freire, P. (1976). A few notions about the word conscientization. In R. Dale, G. Esland, \& M. MacDonald (Eds). Schooling and capitalism. London, England: Routledge.

Freire, P. (1993). Pedagogy of the oppressed (Rev. ed.). New York: Continuum.

Freire, P. (1998). Teachers as cultural workers. Boulder, CO: Westview Press.

Gallagher-Trayhan, E. K. (2010). Sources of resilience of female Mexican American college students enrolled in the McNair scholars program. Our Lady of the Lake University. ProQuest Dissertations and Theses, http://search.proquest.com/docview/751615739?accountid=283

George, P., \& Aronson, R. (2003). How do educators' cultural belief systems affect underserved students' pursuit of postsecondary education? Honolulu, HI: Pacific Resources for Education and Learning

Graham, P.A. (2005). Schooling in America: How the public schools meet the nation's changing need. New York: Oxford University Press.

Gruenwald, D. A. (2003). The best of both worlds: A critical pedagogy of place. Educational Researcher, 32(4), 3-12. 
Grimmett, M. S., Bliss, J. R., \& Davis, D.M. (1998). Assessing federal TRiO McNair program participants' expectations and satisfaction with projects. Journal of Negro Education, 67(4), 404.

Haymes, S. (1995). Race, culture and the city: A pedagogy for Black urban struggle. Albany: State University of New York: Press.

Hardy-Fanta, C. \& Ransford, P. (2010). Facing up: Managing diversity in challenging times. Center for Women in Politics and Public Policy Publications. Paper 14. Retrieved from http://scholarworks.umb.edu/cwppp_pubs/14.

Helms, J.E. (1990). “Womanist” identity attitudes: An alternative of feminism in counseling theory and research. College Park: University of Maryland.

Hsiao, K.P. (1992). First generation college students. ERIC digest (ERIC ED351079)

Horn, L. (1998). Stopouts or stayouts? Undergraduates who leave college in their first year. Washington, D.C.: U.S. Government Printing Office.

Ishitani, T. T., (2006). Studying attrition and degree completion behavior, among firstgeneration college students in the United States. The Journal of Higher Education 77(5), 861-885.

Ishiyama, J. (2007). Expectations and perceptions of undergraduate research mentoring: Comparing first generation, low-income white/Caucasian and African American students. College Student Journal, 41(3), 510-520. 
Jehangir, R. (2009). Cultivating voice: First-generation students seek full academic citizenship in multicultural learning communities. Innovative Higher Education, 34(1), 33-49.

Josselson, R. (1987). Finding herself: Pathways to identity development in women. San Francisco: Jossey-Bass.

Kana’iaupuni, S.K. \& Liebler, C.A. (2005). Pondering poi dog: Place and racial identification of multiracial Native Hawaiians. Ethnic and Racial Studies, 28(4), 687-721. doi: 10.1080/01419870500092852

Kanno, Y. \& Norton, B. (2003). Imagined communities and educational possibilities: Introduction. Journal of Language, Identity and Education, 2(4), 241-249.

Kincheloe, J.L. (2007). Critical pedagogy in the twenty-first century. In P. McLaren \& J. Kincheloe Critical pedagogy: Where are we now? (pp. 9-42). New York: Peter Lang Publishing.

Korpela, K.M. (1989). Place identity as a product of environmental self regulation. Journal of Environmental Psychology, 9. 241-256.

LaFromboise, T.D., Trimble, J.E., \& Mohatt, G.V. (1990). Counseling intervention and American Indian tradition: An integrative approach. The Counseling Psychologist, 18(4), 628-654.

Lalli, M. (1992). Urban related identity: Theory, measurement, and empirical findings. Journal of Environmental Psychology, 12, 285-303. 
Lovitts, B. E., \& Nelson, C. (2000). The hidden crisis in graduate education: Attrition from Ph.D. programs. Academe, 86(6), 44-50.

Madey, D.L. (1982). Some benefits of integrating qualitative and quantitative methods in program evaluation, with illustrations. Educational Evaluation and Policy Analysis, 4, 223-236.

Martinez, M., \& Klopott, S. (2005). The link between high school reform and college access for low-income and minority youth. Washington, D.C.: American Youth Policy Forum and Pathways to College Network.

McCoy, A., Wilkinson, A., \& Jackson, R. Education and employment outcomes of the Ronald E. McNair postbaccalaureate achievement program alumni. U.S. Department of Education, Office of Planning Evaluation and Policy Development, Policy and Program Studies Service. Washington, D.C.

McEwen, M.K. (1996). New perspectives on identity development. In S.R. Komives \& D.B. Woodward, Jr. (Ed.). Student services: A handbook for the profession ( $^{\text {rd }}$ ed., pp. 188-217). San Francisco: Jossey-Bass.

McLaren, P. (1991). Decentering culture: Postmodernism, resistance, and critical pedagogy. Current Perspectives on the Culture of Schools. Boston, MA: Brookline Books

McLaren, P. (1995). Critical pedagogy and predatory culture. New York, NY: Routledge.

Mezirow, J. (1997). Transformative learning in action. New Direction for Adult and Continuing Education, 7, 5-12. 
Miller, J.L. (1990). Creating space and finding voices: Teachers collaborating for empowerment. Albany, NY: State University of New York Press.

Moustakas, C. (1990). Heuristic research: Design, methodology and applications. Newbury Park, CA: Sage.

National Academy of Sciences. (1997). The path to the Ph.D.: Measuring graduate attrition in the sciences and humanities. Retrieved from http://www.nap.edu/openbook.php?record_id=5195\&page=30

National Science Foundation. (2010). Academic research and development: Doctoral Scientists and engineers in academia. Retrieved from http://www.nsf.gov/statistics/seind10/c5/c5s3.htm

Nigrescence. (2010). In Encyclopedia of Identity. Retrieved from http://www.credoreference.com/entry/sageidentity/nigrescence

Nunez, A.M., \& Cuccaro-Alamin, S. (1998). First generation students: undergraduates whose parents never enrolled in post-secondary education (NCES 98-082). Washington, D.C.: National Center for Educational Statistics.

Ogbu, J. U. (1993). Variability in minority school performance: A problem in search of an explanation. In E. Jacob and C. Jordan (Ed.), Minority education: Anthropological perspectives (pp. 83-111). Norwood, New Jersey: Ablex Publishing Corporation.

Olive, T. (2010). Desire for higher education in first-generation Hispanic college students. International Journal Of Interdisciplinary Social Sciences, 5(1), 377389.

Palmer, P. J. (2000). Let your life speak: Listening for the voice of vocation. San Francisco: Jossey-Bass. 
Palmer, R. \& Gasman, M. (2008). “It takes a village to raise a child”: The role of social capital in promoting academic success for African American Men at a Black college. Journal of College Student Development, 49(1), 52-70.

Parker, K.D. (2003). Achieving diversity in graduate education: Impact of the Ronald E. McNair Postbaccalaureate achievement program. Negro Education Review, 54(1/2), 47-50.

Patton, M.Q. (2002). Qualitative research \& evaluation methods. $3^{\text {rd }}$ ed. Thousand Oaks, CA: Sage.

Proshansky, H. M., Fabian, A. K., \& Kaminoff, R. (1983). Place identity: Physical world socialisation of the self. Journal of Enviromental Psychology, 3, 57-83.

Pinar, W. F., Reynolds, W. M., Slattery, P., \& Taubman, P.M. (2004). Understanding Curriculum. New York, NY: Peter Lang.

Rendon, L.I. (1994). Validating culturally diverse students: Toward a new model of learning and student development. Innovative Higher Education, 19(1). 33-51

Rodriguez, A.L., Guido-DiBrito, F., Torres, V., \& Talbot, D. (2000). Latina college students: Issues and challenges for the $21^{\text {st }}$ century. NASPA Journal, 37(3). 511527.

Rosenthal, R., \& Rosnow, R.L. (1991). Essentials of behavioral research: Methods and data analysis. Boston, MA: McGraw Hill.

Seburn, M., Chan, T., \& Kirshtein, R. (2005). A profile of the Ronald E. McNair post baccalaureate achievement program: 1997-1998 through 2001-2002. U.S. 
Department of Education, Office of Postsecondary Education Federal TRiO programs: Washington, D.C.

Smedley, B.D., Myers, H.F., \& Harrell, S. P. (1993). Minority-status stresses and the college adjustment of ethnic minority freshmen. The Journal of Higher Education 64(4). 434-452.

Snyder, B. R. (1970). The hidden curriculum. Cambridge, MA: The MIT Press.

Soja, E. (1989). Postmodern geographies: The reassertion of space in critical social theory. London: Verso.

Stevens, R. A., Jr. (2004). Understanding gay identity development within the college environment. Journal of College Student Development, 45(2), 185-206.

Stevens-Long, J., Schapiro, S.A., \& McClintock, C. (2012). Passionate scholars: Transformative learning in doctoral education. Adult Education Quarterly, 62(2), 180-198.

Stewart, C.J., \& Cash, W.B. (2006). Interviewing principles and practices. New York, NY: McGraw Hill.

Stokes, C. (Producer \& Director). (n.d.). The spirit lives on...A tribute to Dr. Ronald E. McNair [Motion picture]. United States: WBTW

Striplin, J. J. (1999). Facilitating transfer for first-generation community college students. ERIC Digest June, (ERIC ED430627). 
Swail, W.S, Redd, K.E., \& Perna, L.W. (2003). Retaining minority students in high education: A framework for success. ASHE-ERIC Higher Education Report, 30 (20).

Tatum, B.D. (1999). Why are all the Black kids sitting together in the cafeteria?. New York: Basic Books.

Tinto, V. (1975). Dropout from higher education: A theoretical synthesis of recent research. Review of Educational Research, 45(1), 89-125.

Torres, V., Howard-Hamilton, M.F., \& Cooper, D.L. (2003). Identity development of diverse populations: Implications for teaching and administration in higher education. ASHE-ERIC Higher Education Report, 29(6). 1-105.

Torres, V. (1999). Validation of the bicultural orientation model for Hispanic college students. Journal of College Student Development, 40, 285-298.

Torres, V. (2003). Influences of ethnic identity development of Latino college students in the first two years of college. Journal of College Student Development, 44(4), $532-547$.

Torres, V., Howard-Hamilton, M.F., \& Cooper, D.L. (2003). Identity development of diverse populations. ASHE-ERIC Higher Education Report, 29(6).

The Profession. (2011). Chronicle of Higher Education, 58(1), 22-29.

Federal Register. (2012). Applications for new awards; Ronald E. McNair Postbaccalaureate achievement program. Retrieved from https://www.federalregister.gov/articles/2012/05/09/2012 11252/applications-fornew-awards-ronald-e-mcnair-postbaccalaureate-achievement-program\#p-49 
U.S. Department of Education. (2012). Ronald E. McNair Postbaccalaureate achievement program annual performance reports, 2006-07 and 2007-08. Retrieved from http://www2.ed.gov/programs/triomcnair/mcnair-cy-0607.pdf

U.S. Department of Education. (2007). Ronald E. McNair Postbaccalaureate achievement program 2002-05 facts and figures at a glance. U.S. Department of Education, Office of Postsecondary Education. Washington, D.C.

U.S. Demographics. (2011). Chronicle of Higher Education, 58(1), 4.

Thayer, P. B. (2000). Retention of students from first generation and low income backgrounds. Opportunity Outlook, 2-8. (ERIC ED446633)

Vargas, J.H. (2004). College knowledge: Addressing information barriers to college. College Access Services: The Education Research Institute (TERI). Accessed from www.teri.org

Willison, S., \& Gibson, E. (2011). Graduate school learning curves: McNair scholar’s postbaccalaureate transitions. Equity \& Excellence in Education, 44(2), 153-168.

Wyre, D. C. (2011). Set up for success: An examination of the Ronald E. McNair postbaccalaureate achievement programs mentoring component. The University of Southern Mississippi. ProQuest Dissertations and Theses, http://search.proquest.com/docview/868707650?accountid=2837 